TALIA DIXIT $16(2021) 29-58$

\title{
EL ENCOMIO A IGNACIO DE MIGUEL SINCELO (BHG 818): INTRODUCCIÓN, EDICIÓN Y TRADUCCIÓN ANOTADA
}

THE ENCOMIUM TO IGNATIOS OF MICHAEL THE SYNKELLOS (BHG 818): INTRODUCTION, EDITION AND TRANSLATION WITH NOTES

\author{
Álvaro Ibáñez Chacón
}

\begin{abstract}
Resumen: La llamada 'colección anti-fociana' conserva un resumen sintético del encomio al patriarca Ignacio compuesto por un tal Miguel Sincelo. La fecha de composición o el momento exacto de su pronunciación son desconocidos, pero es posible que fuera leído en el aniversario de la muerte del patriarca o de su enterramiento en el Monasterio del Sátiro. A pesar de ser un

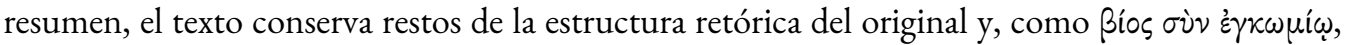
podría ser el modelo sobre el que Nicetas David compuso su Vita Ignatii. Presentamos una nueva edición del texto basada en los principales manuscritos y unas notas exegéticas.
\end{abstract}

Abstract: The so-called 'anti-photian collection' preserves a synthetic summary from the encomium to the Patriarch Ignatios composed by a certain Michael the Synkellos. The date of composition or the exact moment of its pronunciation are unknown, but it is possible that it was read on the anniversary of the Patriarch's death or his burial in the Monastery of Satyros. Despite being a summary, the text conserves traces of the original rhetoric structure and, like a Bios ov̀v $\dot{\varepsilon} \gamma \kappa \omega \mu i \omega$, it could be the model on which Nicetas David composed the Vita Ignatii. This article provides a new critical edition based on the most important manuscripts with exegetical notes.

\footnotetext{
Palabras clave: patriarca Ignacio, Miguel Sincelo, encomio (BHG 818),

edición, hagiografía mediobizantina.

Keywords: Patriach Ignatios, Michael the Synkellos, encomium (BHG 818),

critical edition, Middle-Byzantine hagiography.
}

Fecha de recepción: 3 de octubre de 2021

Fecha de aceptación: 15 de octubre de 2021

\section{Introducción}

$\mathrm{E}$

ntre los documentos que conforman la llamada "colección antifociana”-compilación de textos contra Focio realizada en el s. X por algún miembro del partido ignaciano-se puede leer el extracto del encomio compuesto por un tal Miguel para honrar la memoria y las gestas del difunto patriarca Ignacio. A pesar de lo entrecortado del texto y 
de la reducción hipertextual sufrida, es posible entrever todavía el armazón retórico de la composición original siguiendo la preceptiva bizantina de tradición clásica. La editio princeps, basada en testimonios secundarios, data de principios del s. XVII y se ha reeditado con mínimos retoques desde entonces. Una nueva edición de este y del resto de documentos de la “colección anti-fociana” es tan necesaria como una revisión actualizada del valor histórico de los textos que la componen. ${ }^{1}$

\section{Conservación y autoría}

La "colección anti-fociana" ${ }^{2}$ y el resumen del Encomio a Ignacio ${ }^{3}$ se han conservado en dos ejemplares propiedad del cardenal Besarión ${ }^{4}$ :

- Venezia, Biblioteca Nazionale Marciana, gr. Z 167 (coll. 740), s. XIV ${ }^{\text {in.5 }}$

- München, Bayerische Staatsbibliothek, Cod. graec. 436, s. XIV

De estos dos manuscritos deriva el resto de copias realizadas cuando ya habían sido trasladados por el Cardenal a Italia:

- El Escorial, Real Biblioteca, X-I-5, an. $1545^{7}$

- München, Bayerische Staatsbibliothek, Cod. graec. 27, ca. $1550^{8}$

\footnotetext{
${ }^{1}$ A ello dedicamos las investigaciones realizadas en el marco del Proyecto de Investigación PPJIA2020.01, financiado por el Plan Propio de la Universidad de Granada.

${ }^{2}$ Un listado completo de los textos que la componen en Leonardi-Placanica (2012: lxiv-lxxii) y análisis de los mismos en Dvornik (1948: 216-236).

${ }^{3}$ Dos veces patriarca de Constantinopla y protagonista, junto con Focio, de la tumultuosa historia de la segunda mitad del s. IX. Sobre su vida y obra véanse las síntesis de Oxford Dictionary of Byzantium 983984 (en adelante $O D B$ ), Prosopographie der mittelbyzantinischen Zeit \#2666, \#22712 (abreviado como PmbZ), Prosopography of the Byzantine Empire I Ignatios 1 (abreviatura PBE I), así como el reciente estudio de Prieto Domínguez (2020: 273-329).

${ }^{4}$ Ambos aparecen ya en el inventario de 1468: Labowsky (1979: 165).

${ }^{5}$ Mioni (1981: 246-247), Smithies - Duffy (2013: xviii-xix).

${ }^{6}$ Hardt (1810: 352-354), Van de Vorst - Delehaye (1913: 129), Smithies - Duffy (2013: xviii-xx).

${ }^{7}$ Delehaye (1909: 383), de Andrés (1965: 245-246), Smithies - Duffy (2013: xx-xxi). La fecha exacta ha sido precisada por Martínez Manzano (2018: 355).

${ }^{8} \operatorname{Hardt}$ (1810: 140-156), Van de Vorst-Delehaye (1913: 98), Tiftixoglu (2004: 154-170), Smithies-Duffy (2013: xxv-xxvi). El manuscrito forma parte de la colección de códices que encargó copiar Johann Jakob Fugger entre 1546 y 1556: Mondrain (1991/1992).
} 
- Madrid, Biblioteca Nacional, Ms. 4708, an. $1557^{9}$

- Basel, Universitätsbibliothek, Ms. O II 25, s. XVI ${ }^{10}$

- Vaticano, Biblioteca Apostolica Vaticana, Ottob. gr. 27, s. XVI ${ }^{11}$

- Amsterdam, Universiteitsbibliotheek, Ms. I A 17, s. XVI ${ }^{12}$

- Vaticano, Biblioteca Apostolica Vaticana, Vat. gr. 1183, s. XVI ${ }^{13}$

- Hagion Oros, Movì $\Delta$ เovvoíov 163, s. XVII ${ }^{14}$

A principios del s. XVII, M. Rader publicó la editio princeps bilingüe griego-latín, dedicada al cardenal Baronio y realizada a partir del Cod. graec. 27, cotejado con el Cod. graec. 436. ${ }^{15}$ Desde ese momento la "colección anti-fociana" se ha incorporado a las ediciones de los acta conciliaria con mínimas variaciones en el texto griego y en la traducción latina. ${ }^{16}$ Pero la versión de Rader no era la primera que se había hecho de la colección: a mediados del s. XIV, un dominico del Monasterio de Pera en Constantinopla, el inquisidor de las provincias orientales Filippo de Bindo Incontri, ${ }^{17}$ tuvo acceso a la documentación anti-fociana gracias al erudito filo-latino Demetrio Cidones y, con su ayuda, se llevó a cabo la primera traducción latina de parte de la "colección anti-fociana", ${ }^{18}$ conservada en el manuscrito de Firenze, Biblioteca Centrale Nazionale, Conv. Soppr. C.VII.419, procedente de la biblioteca dominica de Santa Maria Novella. ${ }^{19}$ Sin embargo, esta copia no está completa y faltan, entre otros documentos,

\footnotetext{
${ }^{9}$ De Andrés (1986: 271-272), Smithies - Duffy (2013: xxi-xxiii). Realizado por Cornelio Murmuris ( $R G K$ III 354e) en Venezia el 1557 para Francisco de Mendoza, cardenal de Burgos: de Andrés (1984).

${ }^{10}$ Omont (1886: 399), Van de Vorst - Delehaye (1913: 196), Smithies - Duffy, (2013: xxi-xxii).

${ }^{11}$ Féron - Battaglini (1893: 25), Franchi de'Cavalieri et al. (1899: 251), Smithies - Duffy (2013: xxiv-xxv). Formaba parte de la colección del cardenal Sirleto: Lucà (2012: 325-326).

${ }^{12}$ Omont (1887: 12-13), Mendes da Costa (1902: 14), Smithies - Duffy (2013: xxiii-xxiv).

${ }^{13}$ Franchi de'Cavalieri et al. (1899: 102).

${ }^{14}$ Lambros (1895: 350-351).

${ }^{15}$ Rader (1604). Assemanus (1762: 259) afirmó erróneamente, y en ello ha sido seguido por Smithies Duffy (2013: xxviii-xxix), que también había utilizado el Vat. gr. 1183 y Ottob. gr. 27, pero no hay indicios de ello; véanse Canfora (2004: 7-22) y Luzzi (2019: 471-478) para todo el proceso de publicación.

${ }^{16}$ La última colección que la contiene es la de Mansi (1771: 209-516), dado que la reciente edición de Leonardi - Placanica (2012) solo incluye los acta latinos. Ya en 1606 S. Binius reeditó la traducción latina de Rader en el volumen tercero de sus Concilia generalia et provincialia, pero sin modificaciones; los primeros cambios en el texto griego y en la traducción fueron introducidos en la llamada Editio Romana de los acta conciliaria (1612) y se han repetido sin cuestionarlos.

${ }^{17}$ Estudio biográfico en Loenertz (1948).

${ }^{18}$ Todo lo relativo a esta traducción (texto base, localización, conservación, transmisión, finalidad, etc.) debe ser analizado con detalle; por ahora, véanse los datos que aportan Kaeppeli (1953), Delacroix-Besnier (2003).

${ }^{19}$ Sucintas descripciones en Kaeppeli (1953: 167-168), Pomaro (1982: 236).
} 
la Vita Ignatii atribuida a Nicetas David de Paflagonia $(B H G 817)^{20}$ y el extracto del Encomio a Ignacio objeto del presente estudio. ${ }^{21}$ Nótese, pues, cómo la historia de la transmisión de los documentos antifocianos es muy similar a la de la opera magna de Focio: los ejemplares constantinopolitanos de la Biblioteca pasaron a Occidente a través de Besarión y desde Italia se difundieron por Europa, dando lugar a la editio princeps en 1601 a partir de un reducido número de apógrafos. ${ }^{22}$

Sobre el autor del Encomio a Ignacio no es mucho lo que se puede

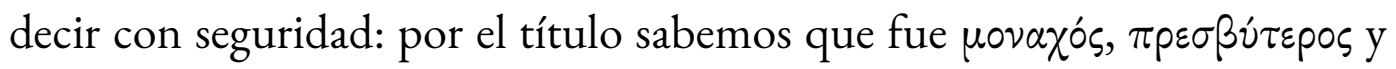
$\sigma \dot{\gamma} \gamma \kappa \varepsilon \lambda \lambda \circ \varsigma$, pero desconocemos dónde vivió o ejerció esos cargos. ${ }^{23}$ Varios son los hagiógrafos homónimos activos en la segunda mitad del s. IX ${ }^{24}$ y de todos ellos el autor del encomio a Ignacio podría ser el Miguel estudita a quien se atribuye la composición de un buen número de panegíricos hagiográficos, la mayoría inéditos: $B H G 127$ a los Ángeles, $B H G$ 956d a S. Isacio y S. Dálmato, $B H G 1147$ a la Virgen, $B H G 1294 a$ a los arcángeles Miguel y Gabriel, $B H G 1298 \mathrm{~h}$ a S. Mocio, $B H G 1881 \mathrm{n}$ a S. Zacarías, así como una de las versiones de la Vida de Teodoro Estudita (versio B, BHG 1754) y ahora se le atribuye también la Vida de Nicolás Estudita (BHG 1365). ${ }^{25}$ Establecer una relación entre el autor del encomio y el protagonista del mismo es difícil, sobre todo si se tiene en cuenta que también ignoramos las circunstancias para las que fue compuesta la laudatio ${ }^{26}$ no obstante, es posible lanzar algunas hipótesis de acuerdo con la práctica bizantina de la época.

\footnotetext{
${ }^{20}$ La edición moderna de Smithies - Duffy (2013) debe consultarse con las justas observaciones realizadas por Luzzi (2019).

${ }^{21}$ Las diferencias de contenido entre los manuscritos constantinopolitanos y la traducción latina pueden deberse a muchos factores: desde la pérdida de texto en el antígrafo hasta la propia selección de los traductores; sin embargo, creemos que la "colección anti-fociana" es el resultado de la acumulación de documentos en diferentes fases, por lo que la versión latina podría haberse realizado a partir de una copia incompleta. Sobre ello trataremos en las XIX Jornadas de Bizancio (Madrid, 2022).

${ }^{22}$ El clásico estudio de Martini (1911) debe ser completado con Canfora (2001).

${ }^{23}$ Una antigua hipótesis sin fundamento lo propuso como sincelo del propio Ignacio: Cave (1688: 562).

${ }^{24}$ Cf. Beck (1959: 503-505), Cunningham (1991: 35-38), Kazhdan (1999: 257-259), Kolia-Dermitzaki (2009: 627-630).

${ }^{25}$ Véanse, entre otros, Krumbacher (1897: 176), Delehaye (1912: 227), Émereau (1924: 411), Loenertz (1950: 103-104), Matantseva (1996), Hatlie (2003), Kazhdan (2006: 204-206), Efthymiadis (2011: 108109), Krausmüller (2013), Prieto Domínguez (2020: 302-319), PmbZ \#503, PBE I Michael 129-130.

${ }^{26}$ Se ha dicho que el encomio fue leído en el "Concilio de la reconciliación” del 879/880 (así Kazhdan, 1999: 258 y Prieto Domínguez, 2020: 216), sin embargo en los acta (ed. Mansi, 1767) no hay rastro de ello.
} 
Como es bien sabido, el aniversario de la muerte de un santo es la celebración capital desde los propios orígenes del culto a los $\operatorname{santos}^{27} \mathrm{y}$, si en el período mediobizantino los patriarcas alcanzaron un status de veneración sin precedentes, incluso en vida, con celebraciones y conmemoraciones anuales, ${ }^{28}$ no es de extrańar que el propio Ignacio, muerto y santificado, fuera objeto de veneración en el aniversario de su muerte. El lugar más indicado para ello sería el Monasterio del Sátiro, reconstruido por el propio Ignacio durante su segundo patriarcado $(c a .873)^{29}$ y donde precisamente fue enterrado y llevó a cabo numerosos milagros post mortem (cf. infra). ${ }^{30}$ En este sentido, el encomio podría haber sido compuesto para la celebración anual de la muerte de Ignacio o bien para conmemorar el aniversario de su enterramiento en el monasterio.

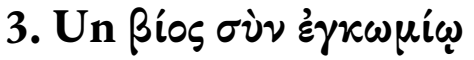

No cabe duda de que el texto conservado en la "colección anti-fociana" es una reelaboración sintética del encomio original: no solo así lo sugiere el

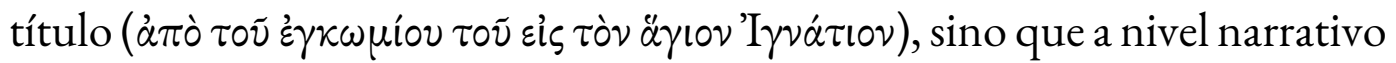
hay una clara alteración en el orden de los hechos y $\$ 4$ encajaría mejor a partir de $\$ 7$, cuando Ignacio ya es patriarca de Constantinopla. En este sentido, no es factible un análisis detallado desde un punto de vista lingüístico o retórico-literario, ${ }^{31}$ pero sí podemos todavía vislumbrar algunos restos del armazón retórico original.

Como es bien sabido, a partir de los Padres de la Iglesia los mártires

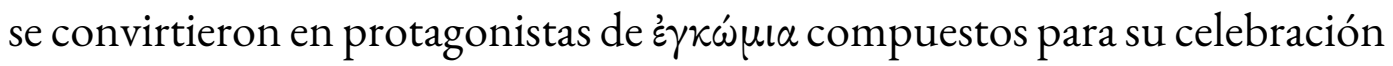

\footnotetext{
${ }^{27}$ Basta con remitir a los estudios de partida de Delehaye (1933) o Brown (1981).

${ }^{28}$ Cf. Loukaki (2011). El patriarca vivo era homenajeado el sábado previo al Domingo de Ramos: Loukaki (2005).

${ }^{29}$ Se localizaría en la vertiente asiática del Bósforo y Pargoire (1901: 73-75), Mamboury (1920: 322-330), Lehmann-Hartleben (1922: 103-106), Janin (1923: 191-193) lo identificaron en la ruinas de Küçükyal1, entre Bostandijk y Maltepe, mientras que Meliópoulos (1927), Eyice (1959: 245-250), Mango (1994: 347 350) o Ricci (1998) creen que estas pertenecen al Palacio de Briante.

${ }^{30}$ Se dice que Ignacio trasladó los restos de su padre, el emperador Miguel I Rangabé, al Monasterio del Sátiro (así Grierson, 1962: 35, o Prieto Domínguez, 2020: 287), pero el texto de Theoph. cont. 1.10.2528 parece indicar que fue el de su hermano Eustracio, cf. Featherstone - Signes Codoñer (2015: 34-35).

${ }^{31}$ Cf., por ejemplo, el análisis de BHG 1294 a realizado por Matantseva (1996: 105-123).
} 
religiosa, sobre todo en la llamada $\pi \alpha \nu \dot{\eta} \gamma v p ı \varsigma^{32}$ dando origen a un subgénero retórico: el panegírico cristiano. ${ }^{33}$ Basados en la teoría de época imperial, especialmente en los dos tratados de retórica de Menandro, ${ }^{34}$ los encomios

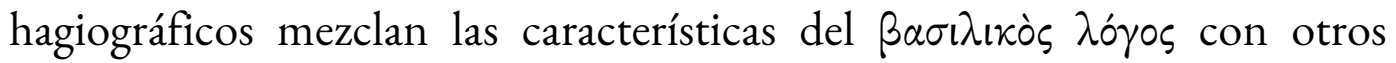

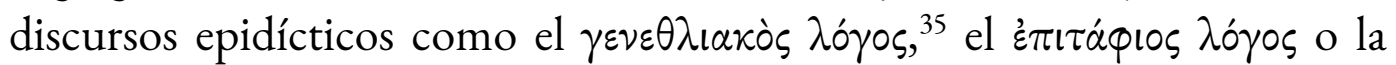
$\mu \circ v \omega \delta i ́ \alpha$ por su carácter luctuoso. ${ }^{36}$

Miguel compuso, por tanto, el Encomio a Ignacio de acuerdo con las convenciones del género y de ello quedan todavía trazas en la síntesis de la "colección anti-fociana", incluyendo las típicas adaptaciones que los autores cristianos introdujeron en el elogio pagano. ${ }^{37}$ Así, la tópica descripción de la $\pi \alpha \nu o \pi \lambda i ́ a$ no tendría cabida en la vida de un santo patriarca $^{38}$ y es sustituida por la anécdota sobre el ¿juopópıov de Santiago adquirido por Ignacio y enviado desde Jerusalén $(\$ 4),{ }^{39}$ palio con el que celebraba los oficios y con el que fue enterrado, como se puede ver en la ilustración del Menologio de Basilio II (Vaticano, Biblioteca Apostolica Vaticana, Vat. gr. 1613, fol. 134r). ${ }^{40}$ Tampoco se conserva la descripción física del personaje, pero sí el episodio de la emasculación de Ignacio como un hecho que reforzaba la virtud y la postura del santo de cara el pecado de

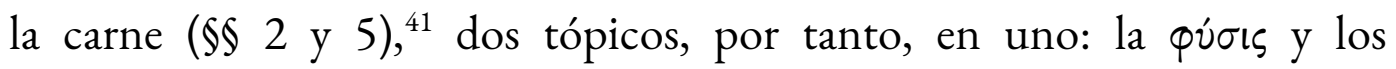
$\dot{\varepsilon} \pi \iota \tau \eta \delta \varepsilon \dot{\mu} \mu \alpha \tau .^{42}$ Otro cambio esperable es la sustitución de la invocación al

\footnotetext{
${ }^{32}$ Stricto sensu era una celebración anual que comenzaba en la vigilia, con cantos y una homilia sobre el santo, cf. Vryonis (1981), Leemans (2003), ODB 755-756.

33 Delehaye (1966: 133-141), Pernot (1993), Aigrain (2000: 121-122), Leemans (2003), Hinterberger (2014: 36-39, que lo considera más una adaptación que un subgéneo), Narro (2019: 45-47), ODB 700701.

${ }^{34}$ Delehaye (1966: 141-142), Leemans (2003: 26-28), Pratsch (2005: 402-404), Hinterberger, (2014: 37), $O D B$ 700. Han de tenerse en cuenta, además, Arist. Rh. 1366a-1368a, Theo rhet. Prog. 109-112, Hermog. Prog. 14-18 o Aphth. Prog. 21-31.

${ }^{35}$ Men. rhet. 412-413, citado según la edición de Russell - Wilson (1981).

${ }^{36}$ Men. rhet. 418-422 y 434-437, cf. Delehaye (1966: 142).

${ }^{37}$ Cf. Bartelink (1986), Mazzucco (1996).

${ }^{38}$ Men. rhet. 374. Las armas son indispensables en la iconografía de los santos militares: Walter (2003), Grotowski (2010).

${ }^{39}$ Cf. Nic. Dav. Vit. Ign. 75.

${ }^{40} \mathrm{La}$ idealizada miniatura fue pintada por Jorge, uno de los ocho artistas que iluminaron el manuscrito, cf. Ševčenko (1962), Zacharova (2009).

${ }^{41}$ Ignacio fue forzosamente castrado por orden de León $\mathrm{V} y$, según algunas fuentes, también los otros hijos de Miguel I, asegurándose de que no tuvieran descendencia que se pudiera volver contra él, cf. Bury (1912: 29), Ringrose (2003: 62), Chadwick (2003: 121).

${ }^{42}$ Men. rhet. 371-372, cf. Pernot (1993: 157-165).
} 
emperador por la єن̉xý a Dios, a los santos o al protagonista santificado ( ( 14). ${ }^{43}$

Así pues, aunque el texto conservado sea una reescritura sintética, es posible detectar algunas de las figuras estilísticas que adornarían el encomio original, sobre todo tropos que tienen como finalidad la

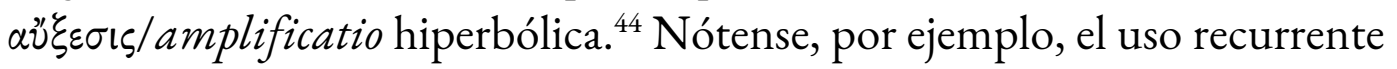

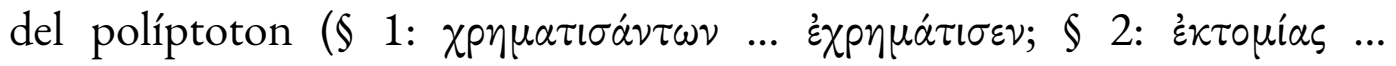
$\dot{\varepsilon} \kappa \tau \mu \eta \theta \tilde{\eta} \nu \alpha \iota)$, a veces en expresiones pleonásticas $(\$ 4: \theta \alpha \nu \dot{\omega} \nu \tau \tilde{\omega} \tau \alpha \dot{\alpha} \phi \omega . .$.

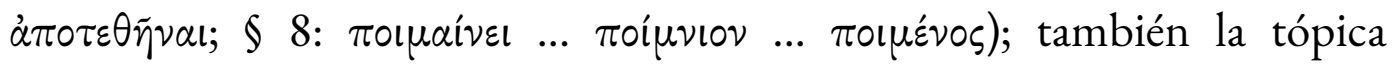

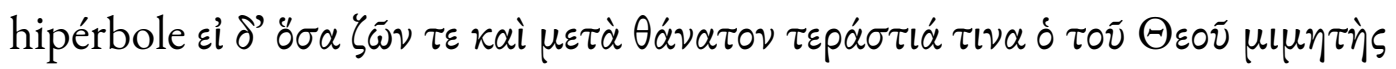

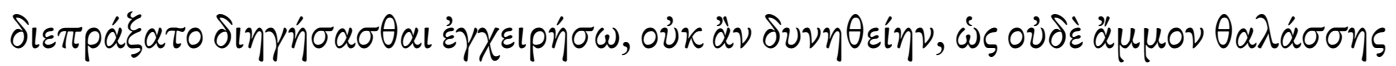

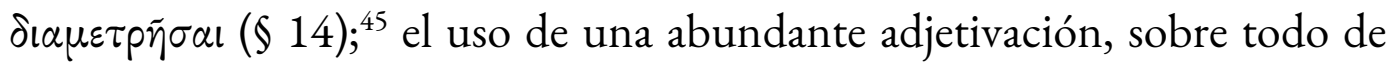

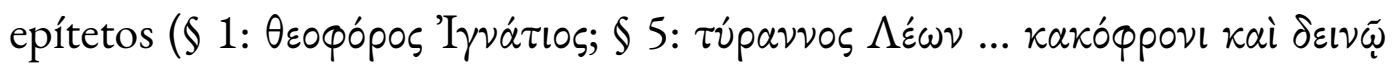

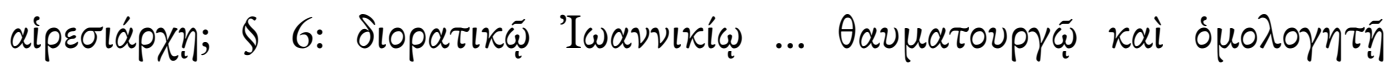

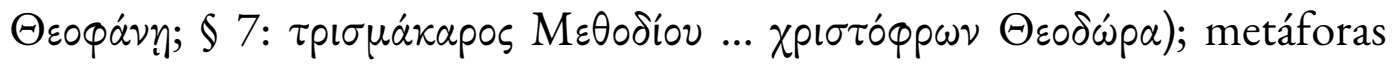

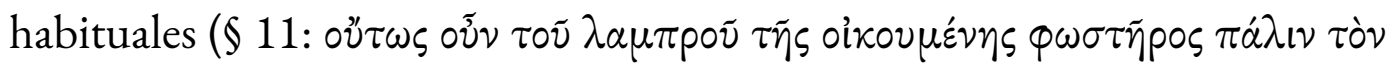

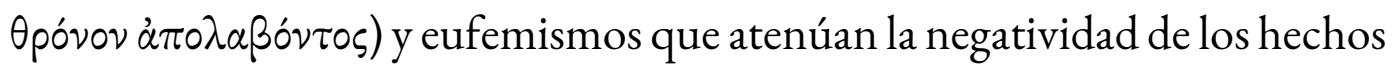

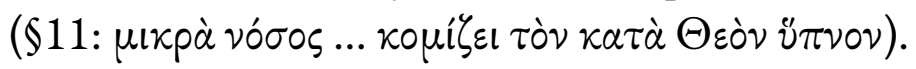

En cuanto al ritmo, es esperable que el autor del extracto haya trastocado la prosa rítmica del original, ${ }^{46}$ pero también quedan restos de ella, sobre todo al inicio del encomio $(\$ 1)$ :

\begin{tabular}{|c|c|}
\hline 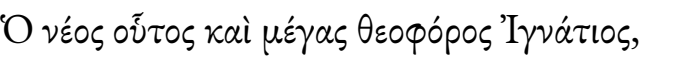 & 16 sílabas / 5 acentos \\
\hline & s/ 2 acentos \\
\hline 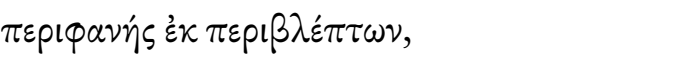 & $s / 2 a$ \\
\hline & s / $2 \mathrm{ac}$ \\
\hline$\alpha \sigma \downarrow \lambda \varepsilon^{\prime} \omega \nu \chi p \eta \mu \alpha \tau \iota c$ & 16 sílabas / 4 acentos \\
\hline
\end{tabular}

Nótense la disposición anular de los miembros, el isosilabismo y la repetida cadencia /xxx/x, a excepción del Doppeldaktylos en la cláusula

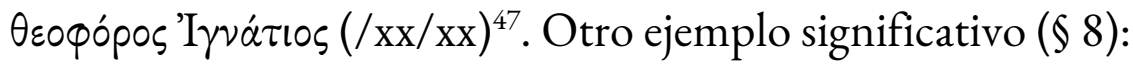

\footnotetext{
${ }^{43}$ Men. rhet. 377. La invocatio es común también en los prólogos hagiográficos: Pratsch (2005: 53-55), Narro (2017: 113).

${ }^{44}$ Omnipresente desde los encomios paganos: Delehaye (1966: 147-150).

${ }^{45}$ Cf. también Nic. Dav. Vit. Ign. 87.

${ }^{46}$ Además del clásico estudio de Hörandner (1981), véanse Lauxtermann (1999) y Valiavitcharska (2013).

${ }^{47}$ Sobre este ritmo Hörandner (1981: 41-46), Valiavitcharska (2013: 63-64).
} 


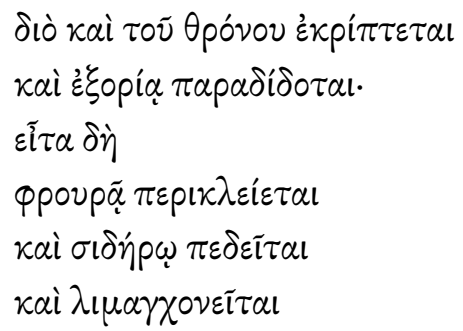
10 sílabas / 3 acentos
10 sílabas / 2 acentos
7 sílabas / 2 acentos
7 sílabas / 2 acentos
6 sílabas / 1 acentos

Además del homoteleuton en la enumeración ascendente de las desgracias, es de señalar la doble cadencia /xx en las dos primeras cláusulas (con "doble dáctilo") y $/ \mathrm{x}$ en las tres últimas, constituyendo un tricolon.

Pasando al contenido, la comparación del encomio con la biografía de Nicetas David (cf. tabla 1) muestra que el epitomador ha seleccionado solo los principales eventos de la biografía del difunto patriarca para elogiarlo, omitiendo hechos negativos como las numerosas calamidades sufridas después de su destitución el 23 de noviembre del $858 ;{ }^{48}$ además, no se hace mención alguna a Focio en el texto conservado, cuando en la Vita Ignatii, en cambio, está tan presente como el propio Ignacio, pero con una caracterización absolutamente negativa. ${ }^{49}$ Los sufrimientos, castigos y tormentos a los que fue sometido Ignacio podrían haber formado parte de la composición original de Miguel, en tanto que tienen el valor retórico de

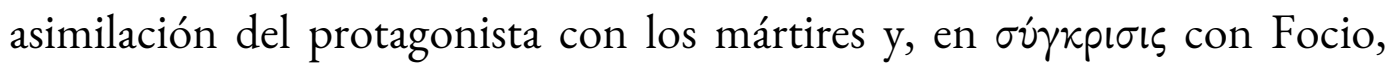
habrían puesto en evidencia los aspectos más elogiables de la personalidad de Ignacio y de su gestión durante el patriarcado. ${ }^{50}$ Pero un encomio no es un documento histórico, sino un ejercicio retórico verosímil basado en el conocimiento de la vida del santo a un nivel más local ${ }^{51} \mathrm{y}$, si por lo general la veracidad de los hechos narrados es inversamente proporcional a la popularidad del santo, ${ }^{52}$ no extrańa que lo expuesto sobre Ignacio haya sido manipulado de manera evidente, sobre todo lo relativo a los miracula y a los signos divinos. Así pues, se debe tener en cuenta que la hagiografía del

\footnotetext{
${ }^{48}$ Los suplicios a los que fue sometido Ignacio están recopilados en Nic. Dav. Vit. Ign. 17-37 y, con menos detalle, en Theoph. cont. 4.31, Gen. 4.18, Scylit. 17, Ps.-Sym. 28, cf. Prieto Domínguez (2014).

${ }^{49}$ Cf. Vinson (1998). Según Prieto Domínguez (2020: 317-319), Miguel presenta un texto conciliador que exonera a Focio de las maldades atribuidas por los ignacianos; sin embargo, esto no encaja en el tono claramente anti-fociano de la colección.

${ }^{50}$ Cf. como tópico en Delehaye (1966: 152-154), Leemans (2003: 30-31), Pratsch (2005: 170-183), Crimi (2018: 83-85).

${ }^{51}$ Delehaye (1966: 165-169), Aigrain (2000: 123-124); para la relación entre biografía clásica y hagiografía véase van Uytfanghe (2005).

${ }^{52}$ Delehaye (1906: 242-244).
} 
período mediobizantino aportó cierta frescura y novedad a la tradición precedente: los nuevos santos llevan a cabo distintas gestas, sus tormentos no fueron tan terribles, sus muertes menos violentas, etc. ${ }^{53} \mathrm{El}$ santo está más humanizado y no habita ya en lugares lejanos e inaccesibles, sino en la ciudad, ocupando cargos políticos o eclesiásticos, ${ }^{54}$ lo que no impide, sin embargo, que se le atribuyan milagros y hechos sorprendentes.

Comenzando por los signos divinos, mientras que en la Vita Ignatii se registran cuatro seísmos como advertencia por las negativas acciones humanas, ${ }^{55}$ en el extracto del encomio solo queda testimonio del terremoto acaecido en el 862,56 asociado a la destitución oficial de Ignacio en las fuentes, ${ }^{57}$ pero en el encomio se dice que quedó sin una explicación precisa ( $\$$ 9: oủx $\tilde{\eta} v \dot{\delta} \sigma \nu v(\omega \dot{\nu})$ ). Nicetas David narra, además, otras señales divinas: los búfalos desbocados que corrieron en estampida por Santa Sofía (Vit. Ign. 65) o la epifanía del Espíritu Santo cada vez que Ignacio celebraba los oficios (Vit. Ign. 69), pero nada de ello queda en el extracto de la laudatio.

En cuanto a los miracula, aunque en este período no son imprescindibles para obtener la santidad, ${ }^{58}$ las acciones milagrosas son muy frecuentes, a imitación de los grandes mártires del pasado. ${ }^{59}$ Así, según Nicetas David, Ignacio habría realizado numerosos milagros post mortem, ${ }^{60}$ y, como puede observarse (tabla 2), son de tipo terapéutico y tienen lugar en el santuario del santo per contactum con su cuerpo o sus reliquias (p. ej. mir. 1 y 2$)^{61}$, pero también de tipo incubatorio mediante sueños y visiones (p. ej. mir. 4 y 5) $)^{62}$ y otros milagros a distancia (mir. 6-11). Los $\theta \alpha u ́ \mu \alpha \tau \alpha$

\footnotetext{
${ }^{53}$ Síntesis en Pratsch (2005: 408-421).

${ }^{54}$ Rydén (1986), Flusin (1993), Mango (2005).

${ }^{55}$ Función principal en la literatura bizantina, cf. Dagron (1981), reimpreso en Dagron (2012: 3-22), Vercleyn (1988). A la negatividad del hecho se añaden otras catástrofes como el ataque de los rusos que refiere Nicetas David en la Vit. Ign. 47 o el propio Focio en las homilías 3 y 4, cf. Casas Olea (2020: 108$125,251-255)$.

${ }^{56}$ Downey (1955: 599), Grumel (1958: 479).

${ }^{57}$ Según Nic. Dav. Vit. Ign. 39 los temblores cesaron cuando Ignacio, que estaba desaparecido, compareció ante Bardas.

${ }^{58}$ Esta se podía obtener, por ejemplo, habiéndose mostrado contrario a la iconoclastia: Kaplan (2000).

${ }^{59}$ Síntesis en Pratsch (2005: 225-297); cf. también Narro (2017) para los tópicos de las colecciones de miracula anteriores.

${ }^{60}$ Estos son los milagros más comunes desde la Antigüedad Tardía: Krötzl (2018).

${ }^{61}$ A lo largo de la Vita Ignatii se citan los trozos del féretro y del sudario, sus cabellos, el aceite sagrado y los grilletes que una vez lo aprisionaron, nada de lo cual se ha conservado; sí, en cambio, se preservaron reliquias de Focio: Meinardus (1970: 241).

${ }^{62}$ Pratsch (2005: 228-244), Narro (2015/2016) y (2018).
} 
acontecidos en el santuario tienen un evidente carácter propagandístico, ${ }^{63}$ aunque con el paso del tiempo las peregrinaciones masivas comenzaron a decaer y los santos realizaban sus milagros a distancia. ${ }^{64}$ Los miracula de Ignacio se encuentran todavía en un estado intermedio y son dignos de mención los siguientes:

- Mir. 2 (Vit. Ign. 76 y encomio $₫ 12$ ): preparados los restos del santo para ser trasladados al Monasterio del Sátiro, se desencadenó una terrible tempestad y justo en el momento de embarcar el féretro, el temporal amainó y permitió el viaje hasta el locus sanctus. ${ }^{65}$ Este tipo de $\theta$ av́ $\alpha \tau \tau \alpha$ atmosféricos es muy común desde el Antiguo Testamento y, en este caso concreto, representa una inversión de los llamados "rain miracles". ${ }^{66}$

- Mir. 6(Vit. Ign. 83): había dos mujeres que sufrían de agalaxia, pero gracias a la

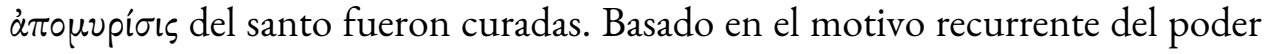
milagroso de cualquier líquido que ha estado en contacto con el cuerpo de un santo, sobre todo el aceite de las lucernas, la cera o el propio $\mu \nu$ pov que destilaban

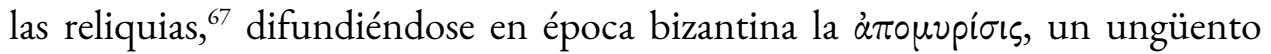
especial hecho de aceite perfumado con alguna reliquia del santo dentro; ${ }^{68}$ aquí se usan los cabellos de Ignacio ( $\tau \tilde{\omega} \nu \dot{\alpha} \gamma \dot{\gamma} \omega \nu$ a $\tilde{\tau} \tau \tilde{\nu} \tau p \imath \chi \tilde{\omega} \nu)$. Hay quien ha destacado la contrariedad de este y otros milagros de fertilidad realizados por un santo eunuco e infértil, ${ }^{69}$ pero, como ha señalado $S$. Tougher, ${ }^{70}$ estos hechos acentúan la masculinidad del venerado patriarca; en este sentido, por utilizar la terminología dumeziliana, la castración de Ignacio se habría convertido en una mutilación "paradójicamente cualificadora". ${ }^{71}$

- Mir. 8 (Vit. Ign. 85): el más significativo de los $\theta$ av́ $\mu \tau \tau \alpha$ a distancia, pues se dice

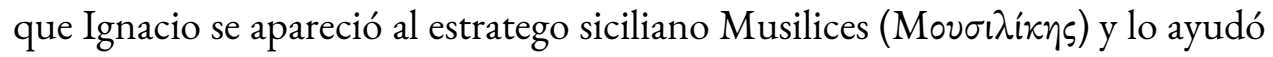
en la guerra contra los árabes. ${ }^{72}$ Aunque este tipo de milagro no terapéutico pierde importancia a lo largo del Medievo, ${ }^{73}$ aquí se recurre al tópico de la guerra

\footnotetext{
${ }^{63}$ Narro (2015/2016: 108-109), Csepregi (2011: 17-30).

${ }^{64}$ Cf. Krötzl (2000: 557-576).

${ }^{65}$ El mar es un espacio tópico de la hagiografía mediobizantina de la capital y de provincias: Efthymiadis (2018), Von Falkenhausen (2018).

${ }^{66}$ También frecuentes en la hagiografía tardoantigua: Stathakopoulos (2002).

${ }^{67}$ Véanse, entre otros, Caseau (2005), Talbot (2015), Narro (2019b).

${ }^{68}$ Ruggieri (1993).

${ }^{69}$ Vinson (1998: 488-491).

70 Tougher (2004: 98-102).

${ }^{71}$ Dumézil (1996: 265-283).

${ }^{72}$ Personaje indudablemente histórico ( $P m b Z$ \#25430, PBE I Mousilikios 1), el milagro, sin embargo, no se cita en ninguna otra fuente; a pesar de esto, la referencia se ha utilizado para establecer el terminus post quem de la composición de la Vita en el 882: Tamarkina (2006: 623). Véase ahora Luzzi (2020).

${ }^{73}$ Krötzl (2000: 570).
} 
contra el enemigo musulmán, ${ }^{74}$ equiparando a Ignacio con el grupo de los santos militares, tan venerados en Bizancio. ${ }^{75}$

- Mir. 12 (Vit. Ign. 87): los miracula no solo eran positivos o beneficiosos para los fieles, sino que también podían castigar a los impíos ${ }^{76}$ y así, según Nicetas David, el propio Focio habría enviado a su sakellarios - del que nada más se sabepara profanar el santuario y las reliquias, pero murió ahogado por su propia sangre.

La Vita Ignatii registra un buen número de $\theta \alpha v ́ \mu \alpha \tau \alpha$ ignacianos, pero en el encomio se refería uno no recogido por Nicetas David ( $\$ 13)$ y según el cual Ignacio, durante su exilio en Mitilene, habría conseguido dominar el curso desbordado del río Lico mediante sus súplicas a Dios. He aquí un miraculum in vita tópico en la hagiografía mediobizantina por imitación del Nuevo Testamento, manifestando el poder sobre la naturaleza de los santos todavía vivos. ${ }^{77}$ El hecho de que no aparezca en la obra de Nicetas David podría ser indicio de la existencia de una primera biografía de Ignacio posteriormente reelaborada y amplificada, ${ }^{78}$ una versión previa que tendría una dimensión local y más modesta, quizá realizada en el Monasterio del Sátiro por un monje cercano a Ignacio, mientras que la reescritura de Nicetas David ofrece una visión más tópica, universal y parcial del personaje; ${ }^{79}$ de hecho, se podría decir que la biografía es un texto antifociano y el encomio pro-ignaciano. Ante la ausencia de datos, incluso se podría plantear la hipótesis de que ese modelo biográfico previo fuera el de Miguel sincelo.

Así, el texto conservado en la "colección anti-fociana” es en realidad

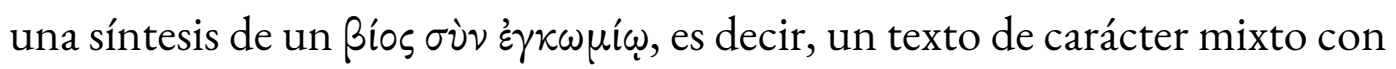
abundantes datos biográficos escogidos y organizados a modo de encomio. ${ }^{80} \mathrm{La}$ composición retórica del original se ha visto irremediablemente adulterada durante el proceso de reducción hipertextual sufrido, pero conservando todavía algunos tópicos, figuras estilísticas y

\footnotetext{
${ }^{74}$ Cf. Kazhdan (1984).

${ }^{75}$ Delehaye (1975), Walter (2003), White (2013).

${ }^{76}$ Narro (2015/2016: 94).

77 Pratsch (2005: 277-288).

${ }^{78}$ Cf. Karlin-Hayter (1970: 217-218). El mismo proceso se ha postulado para la Vida de Gregorio de Agrigento (BHG 708), reescrita por Nicetas David a partir de la biografía-hagiográfica de Leoncio de Roma (BHG 707): Krausmüller (2001/2002), Crimi (2016).

${ }^{79}$ Cf. Crimi (2016: 403-410) para la Vida de Gregorio.

${ }^{80}$ Hinterberger (2014: 44-47).
} 
restos del ritmo original. El autor del encomio podría ser un hagiógrafo compositor de numerosos elogios, pero también un monje del Monasterio del Sátiro, cercano a Ignacio, que pudo tener acceso a una biografía previa o, incluso, haberla realizado él mismo con forma de encomio para la celebración anual de la muerte o deposición del santo. A la hora de ser incorporado a la "colección anti-fociana", el compilador habría realizado una síntesis del encomio dejando solo las secuencias biográficas más significativas y aquellos hechos que no figuraban en la versión extendida del Bíos de Nicetas David que encabezaba la compilación.

\section{Edición crítica}

La presente edición del texto se basa en los dos manuscritos venecianos propiedad del cardenal Besarión:

- Venezia, Biblioteca Nazionale Marciana, gr. Z 167 (coll. 740), s. XIV ${ }^{\text {in. }}, B H G 818$ en fols. 37r-38r, sigla $\mathbf{V}$.

- München, Bayerische Staatsbibliothek, Cod. graec. 436, s. XIV, BHG 818 en pp. 29-31, sigla $\mathbf{B}$.

La relación entre ambos manuscritos no está del todo clara, pues aunque $\mathbf{B}$ parece derivar de $\mathbf{V}$, hay errores y variantes que no solo pueden achacarse al descuido del copista. ${ }^{81}$ El texto del encomio es muy breve, pero nótese $₫ 1$

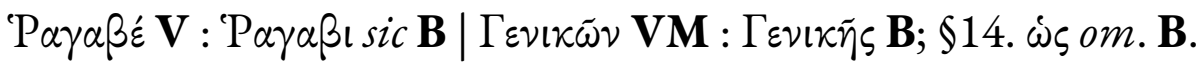

El texto base utilizado por Rader para la editio princeps fue el München, Bayerische Staatsbibliothek, Cod. graec. 27, BHG 818 en fols. 323r-324v, sigla $\mathbf{M}$, claramente un apógrafo de $\mathbf{V}$. La copia $\mathbf{B}$ solo fue utilizada de forma aislada y en anotaciones marginales (indicada como C.B. = codex Bavaricus), utilizándola como ejemplar de colación y de integración en las omisiones que presenta $\mathbf{M}$. Al propio Rader se pueden atribuir las correcciones que indicamos como $\mathbf{M}^{2}$, dado que coinciden con su texto: $\$ 6$

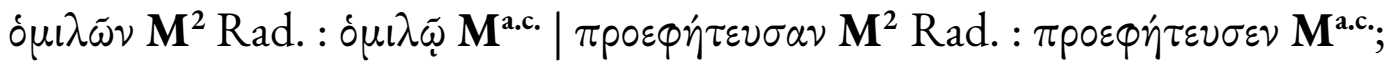

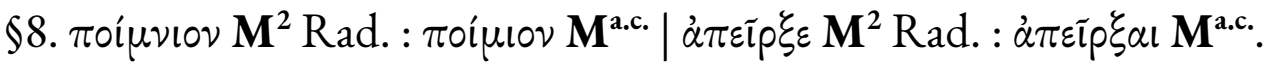

\footnotetext{
${ }^{81}$ Las opiniones expuestas por Smithies-Duffy (2013: xvii-xx) para la Vita Ignatii deben ser revisadas y documentadas con más ejemplos, cf. Luzzi (2019: 471-478).
} 
Además de estos tres ejemplares manuscritos y de la editio princeps, se ha cotejado también el texto de la llamada Editio Romana de los acta conciliaria (abreviada como Rom.), ya que introduce una serie de modificaciones al texto y a la traducción de Rader que se han afincado en el resto de colecciones conciliares, produciendo algunas malinterpretaciones sobre la naturaleza de la príncipe. ${ }^{82}$ Algunos casos significativos: $₫ 8$.

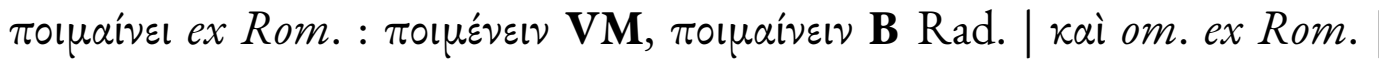

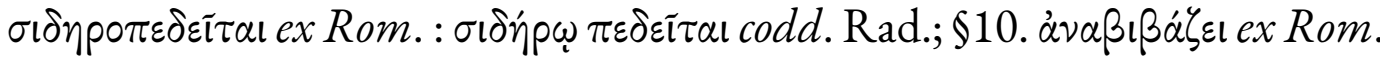

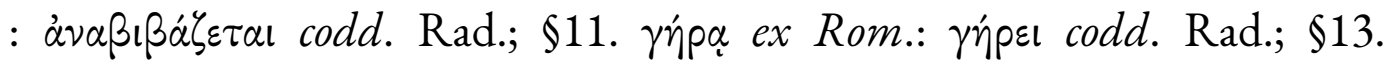

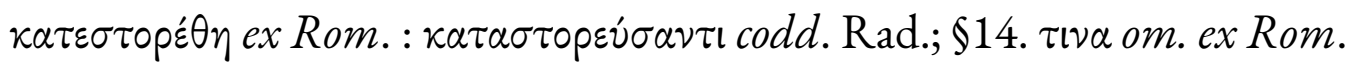

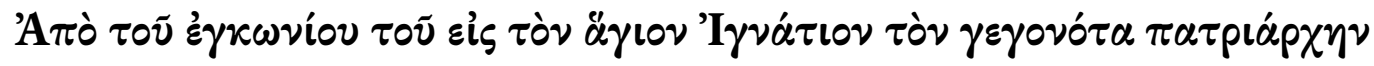

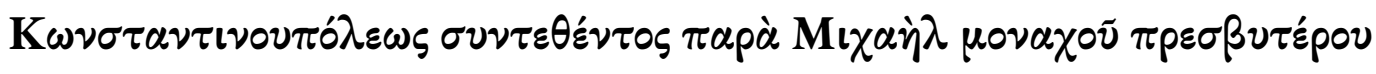

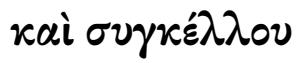

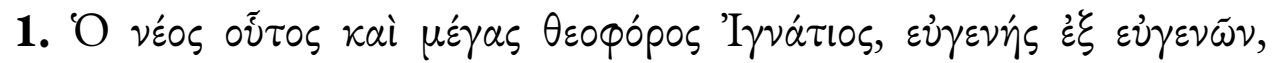

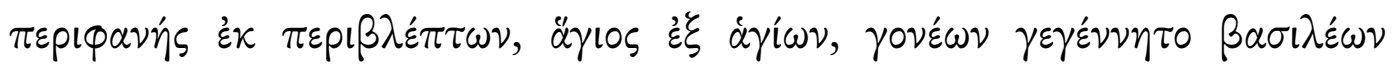

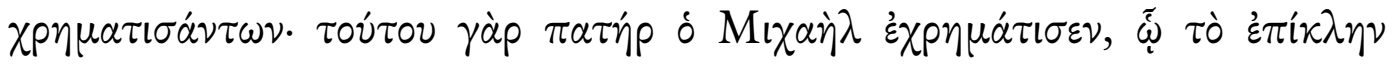

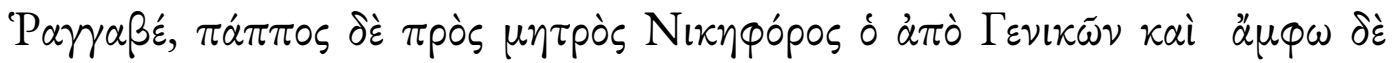

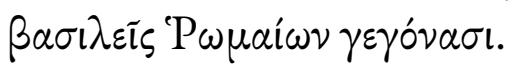

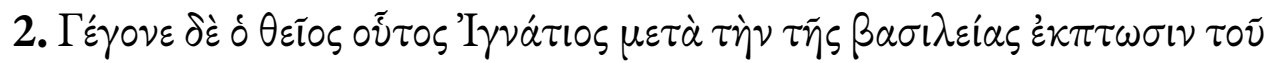

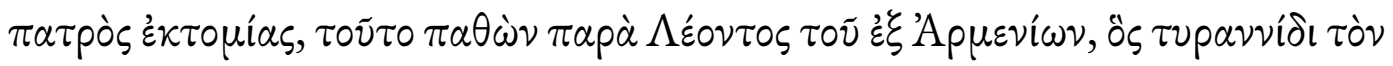

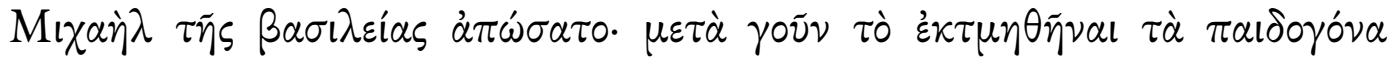

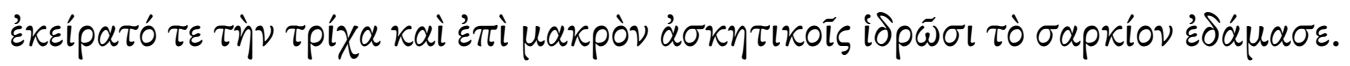

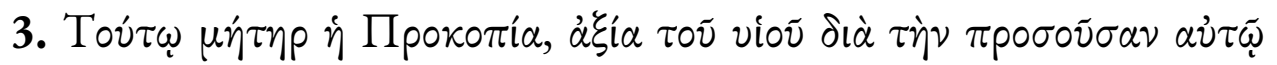

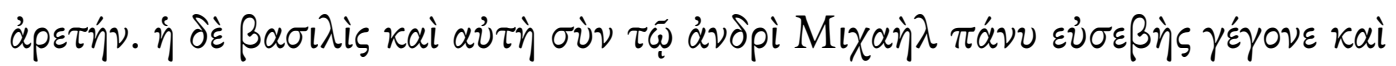

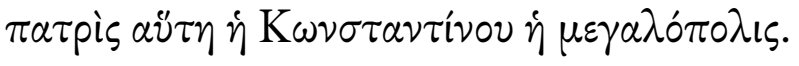

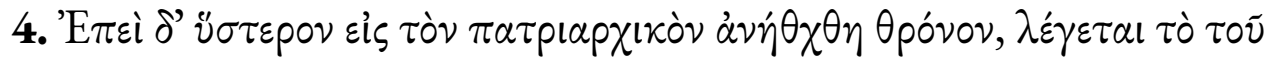

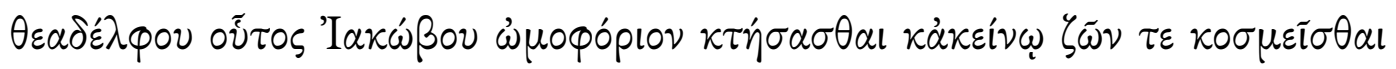

\footnotetext{
${ }^{82}$ Como bien advierte Luzzi (2019: 478-479), los comentarios e hipótesis de Smithies-Duffy (2013: xxviiixxix) sobre la obra de Rader están viciados de entrada al no haber consultado el original de 1604, sino las reediciones modificadas.
} 


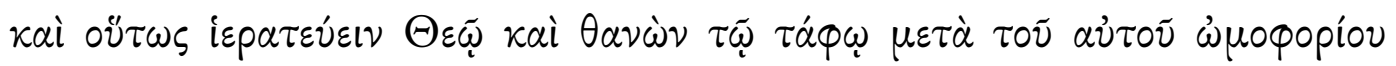
$\dot{\alpha} \pi \circ \tau \varepsilon \theta \tilde{\eta} \nu \alpha$.

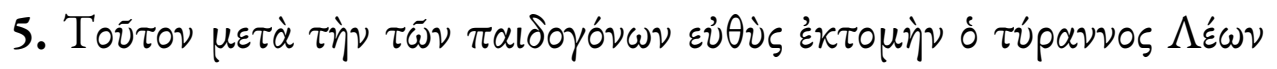

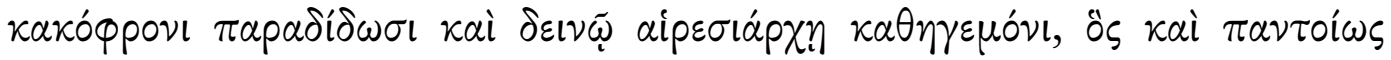

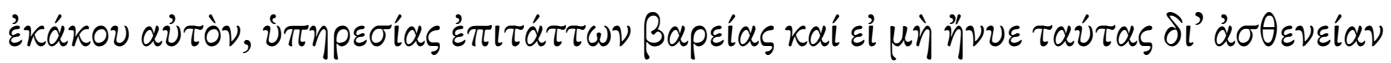

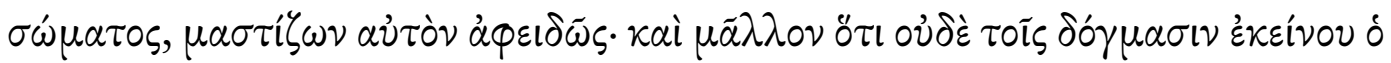

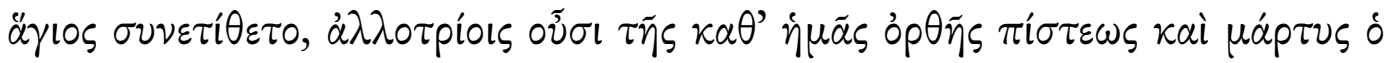

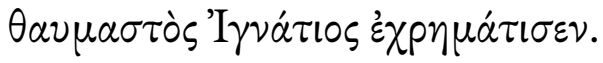

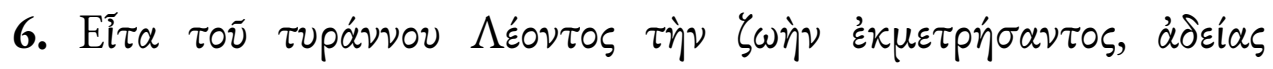

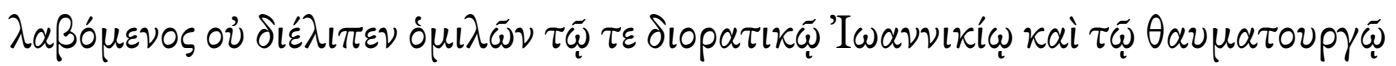

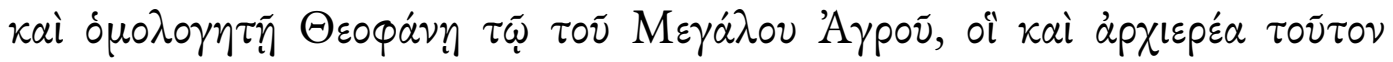

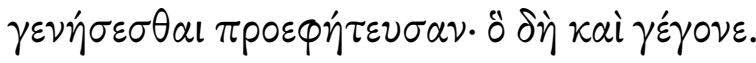

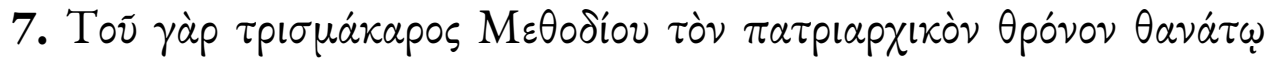

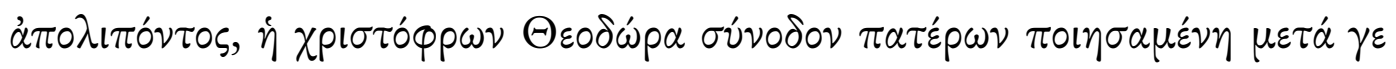

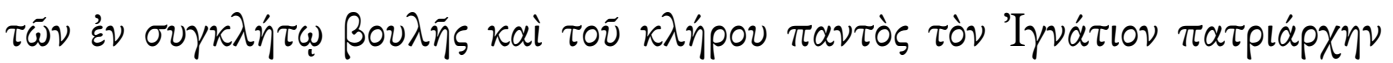
$\kappa \alpha \theta i \sigma \tau \eta \sigma$.

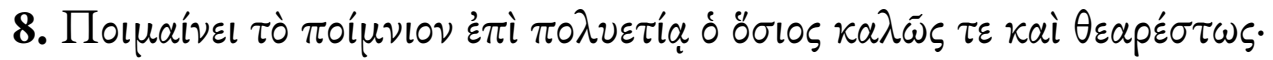

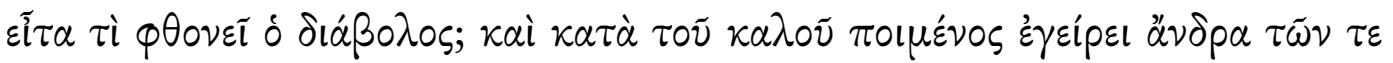

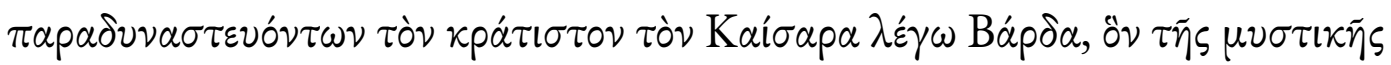

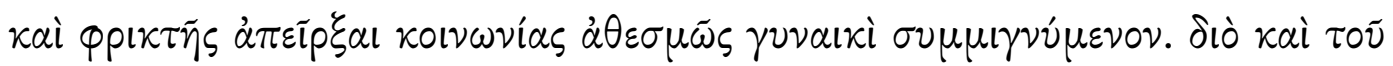

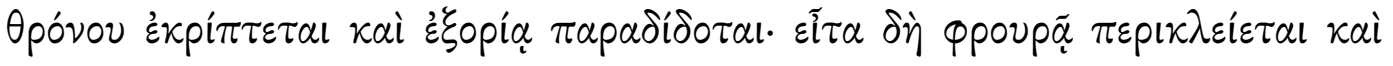

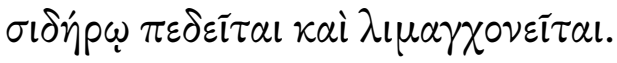

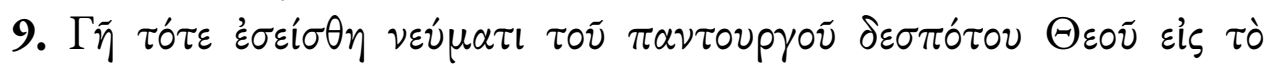

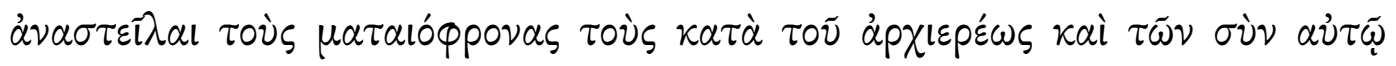

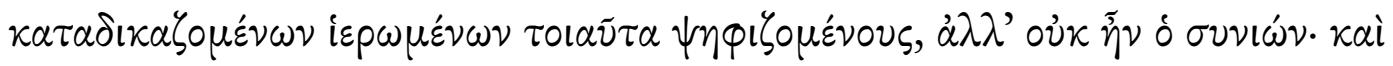

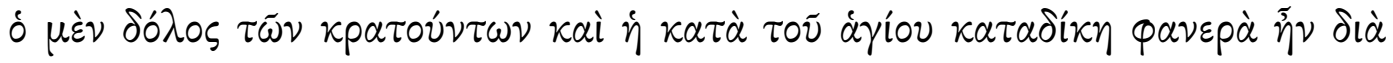

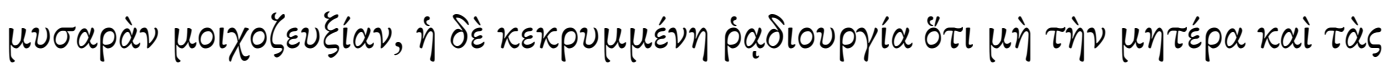

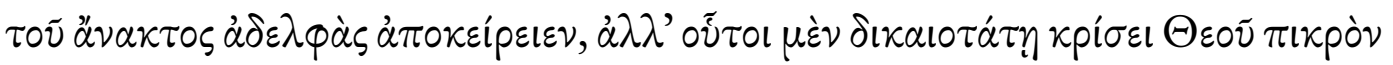

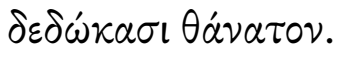

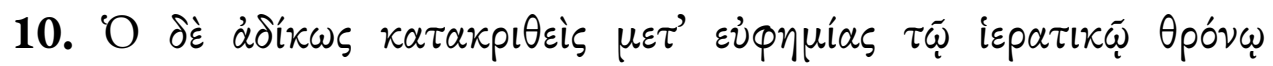

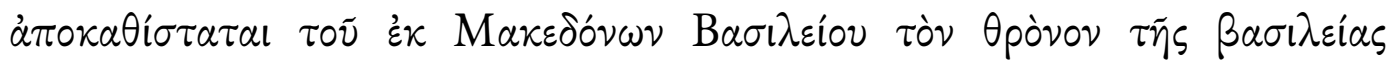

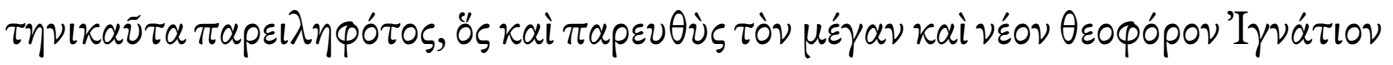

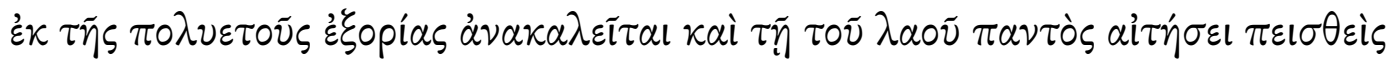

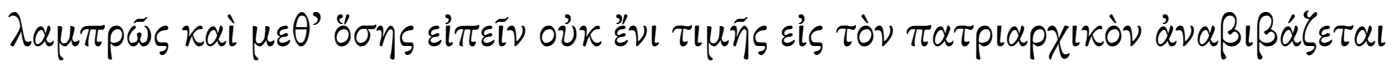

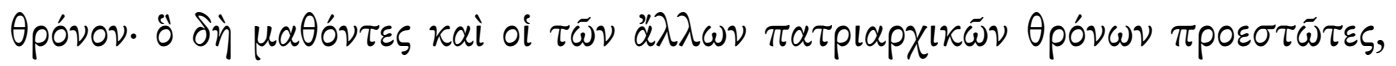

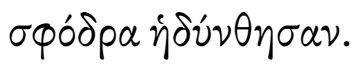




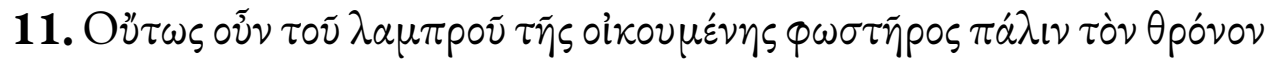

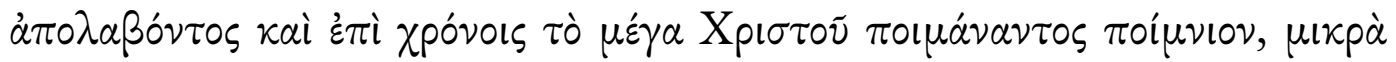

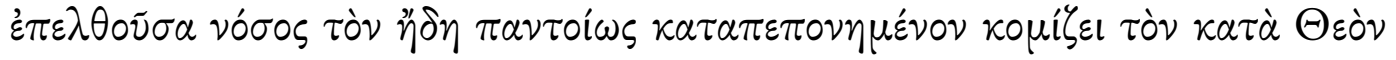

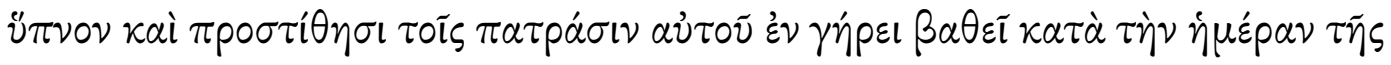

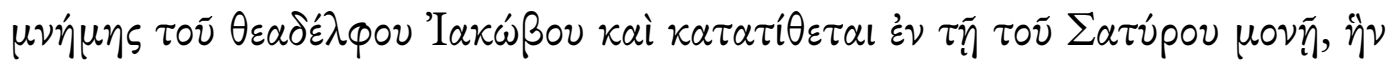

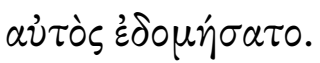

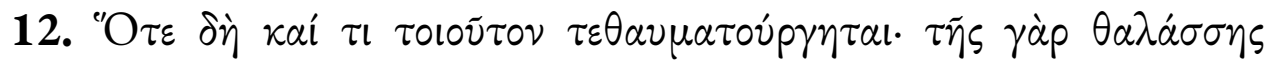

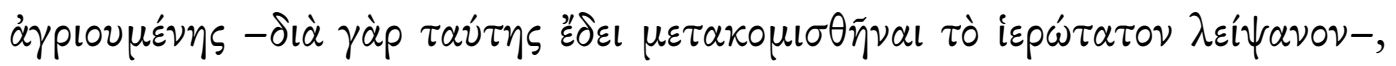

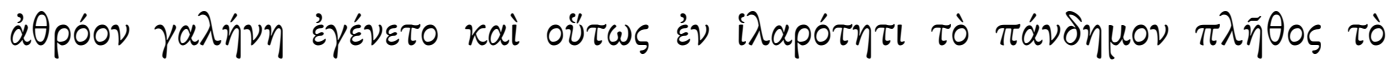

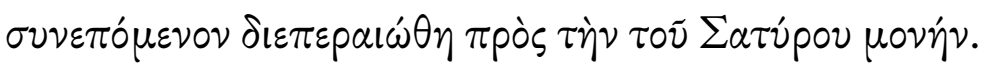

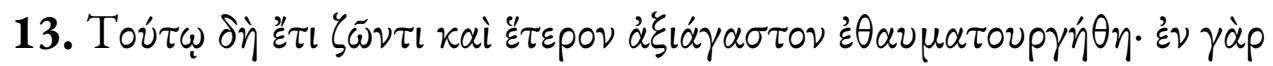

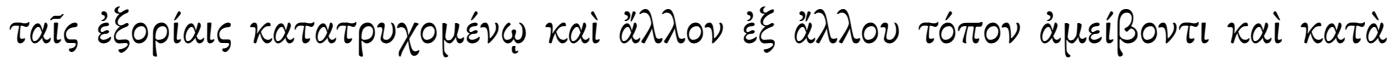

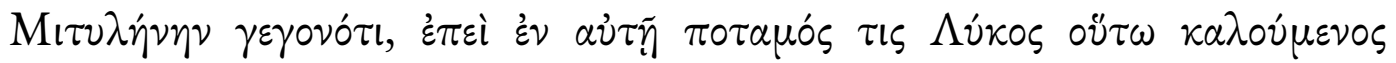

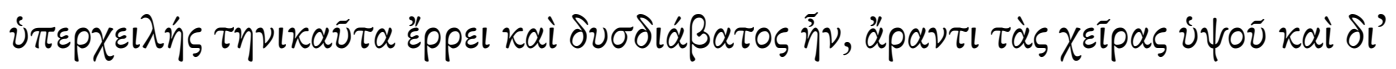

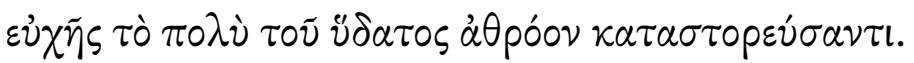

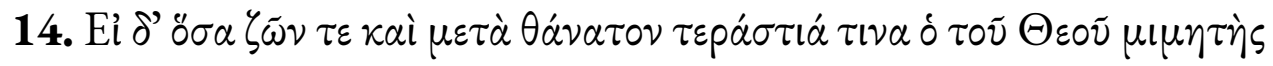

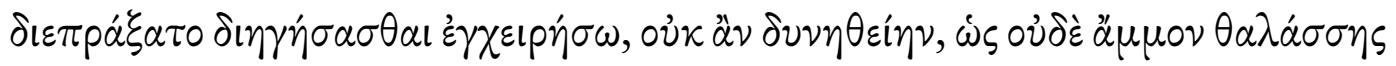

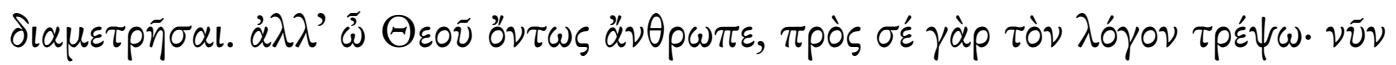

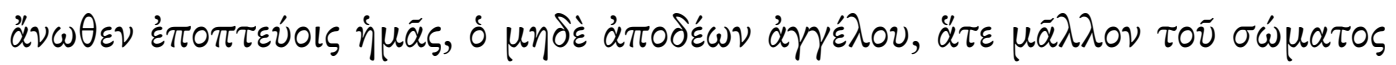

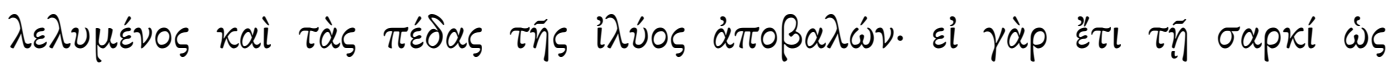

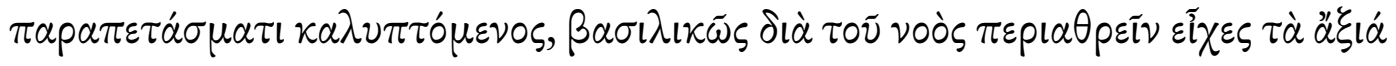

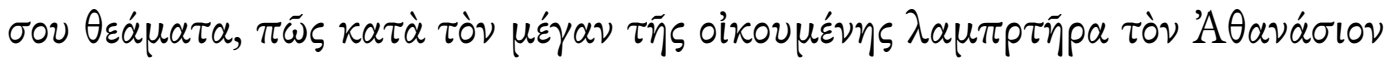

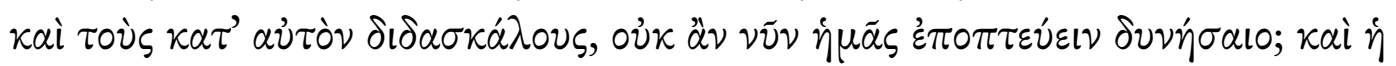

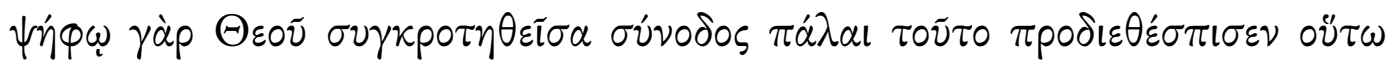

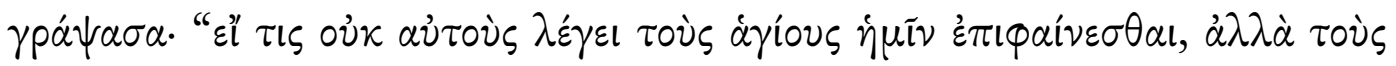

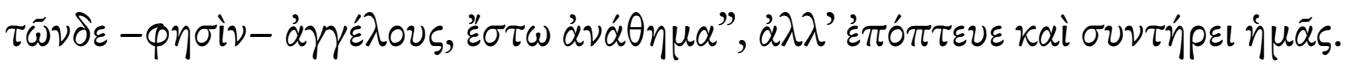

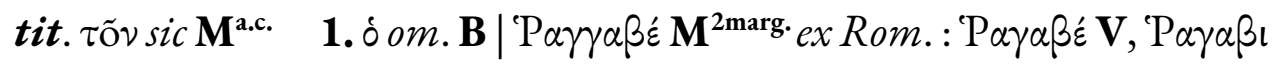

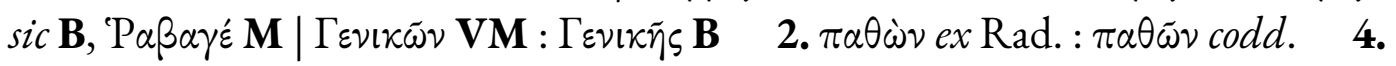

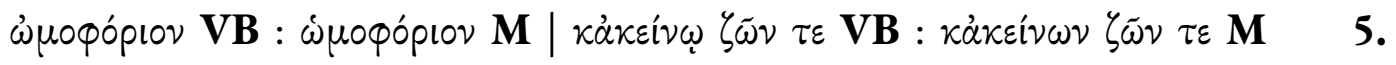

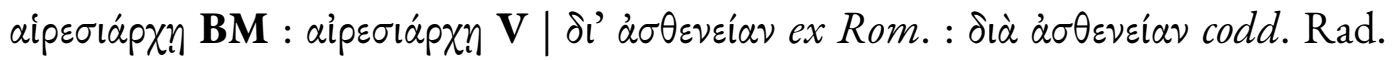

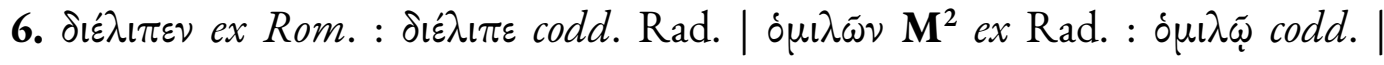




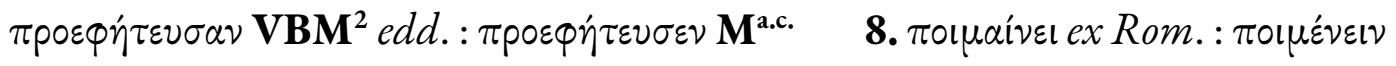

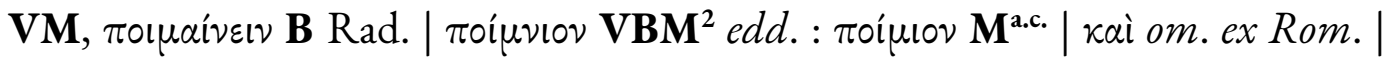

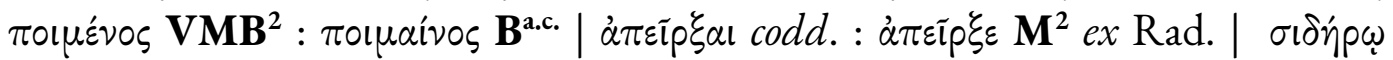

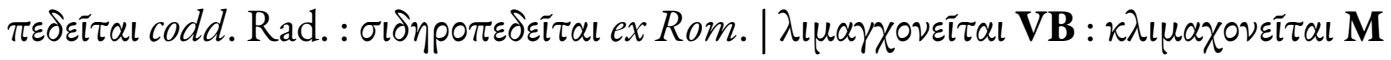

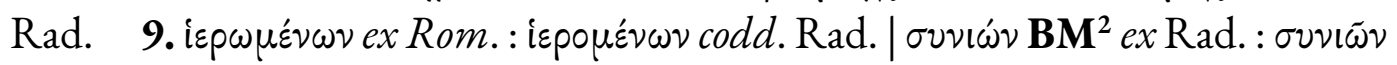

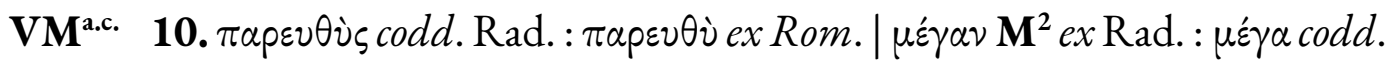

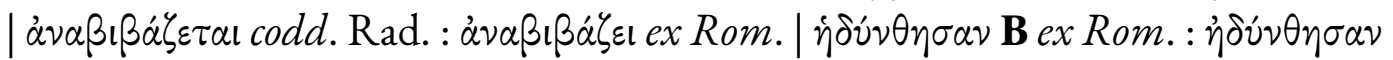

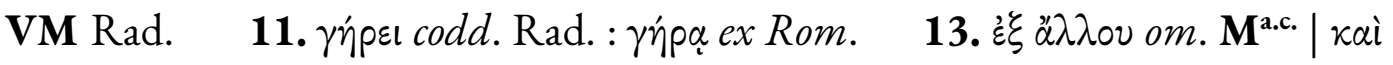

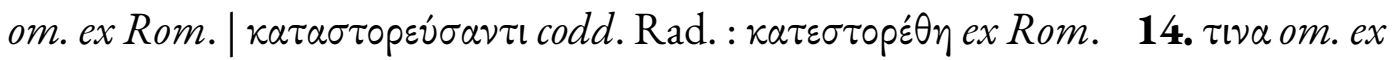

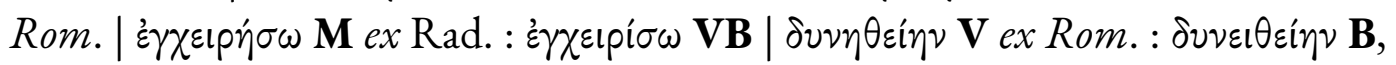

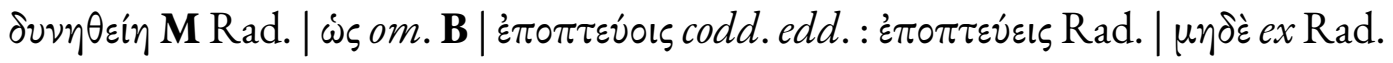

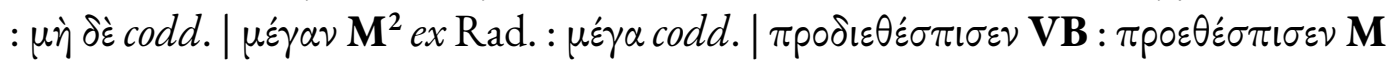
ex Rad. | $\tau \tilde{\omega} \nu \delta \varepsilon \operatorname{codd} . e d d .: \tau \tilde{\omega} \nu \delta \dot{\varepsilon} \mathrm{Rad}$.

\section{Traducción y notas}

\section{Del Encomio a san Ignacio, que fue patriarca de Constantinopla, compuesto por Miguel, monje, presbítero y sincelo}

1. Este magnífico y grande, Ignacio, el enviado de Dios, noble entre nobles, sobresaliente entre ilustres, santo entre santos, era descendiente de la familia imperial, pues su padre fue Miguel, el apodado Rangabé, y su abuelo por parte de madre fue Nicéforo el génico, y ambos habían sido emperadores de los romeos. ${ }^{83}$

2. Después de perder su padre el trono, el divino Ignacio fue castrado, ${ }^{84}$ sufriendo esto por orden de León el Armenio, quien a la fuerza había

\footnotetext{
${ }^{83}$ Miguel I Rangabé, que era patricio, gobernó en 811-813 (ODB 1362, PmbZ \#4989, PBE I Michael 1), tras haberse casado con Procopia ( $P m b Z$ \#6351; PBE I Prokopia 1), hija del emperador Nicéforo I (802811: ODB 1476-1477, PmbZ \#5252, PBE I Nikephoros 8); el texto lo recuerda por haber ejercido de

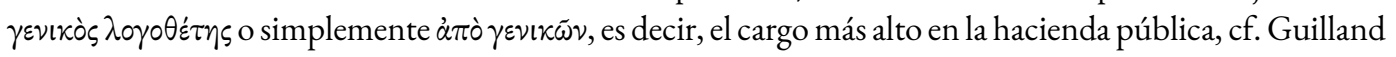
(1971:11-24), ODB 829-830.

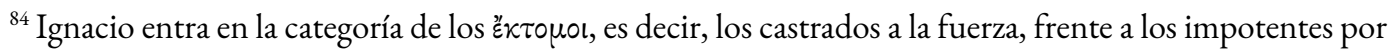

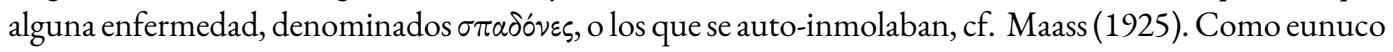
fue representado Ignacio en el tímpano norte de Santa Sofía y en buena parte de las escasas representaciones que se conservan, mientras que existió otro tipo barbado que dio lugar a algunas miniaturas, cf. Mango - Hawkins (1972: 9-11, 28-30); para la iconografía de sus sellos Cotsonis (2011).
} 
expulsado a Miguel del trono. ${ }^{85}$ Así, tras habérsele cortado los genitales y tonsurado el cabello, dominó todavía más la carne con disciplina ascética. ${ }^{86}$ 3. Su madre era Procopia, digna de su hijo gracias a la virtud que imprimió en él. La emperatriz fue muy piadosa, como su marido Miguel, y su patria era la gran ciudad de Constantino. ${ }^{87}$

4. Cuando después hubo alcanzado la sede patriarcal, se dice que adquirió el palio de Santiago, el hermano de Dios, y que, mientras vivió, lo llevaba puesto y de esa manera así realizaba los oficios de Dios y, cuando murió, fue enterrado con su palio. ${ }^{88}$

5. Tras la emasculación, en seguida el tirano León lo confía a un malvado y terrible heresiarca como preceptor, que lo maltrataba de todas las formas posibles, imponiéndole unas duras tareas y azotándolo sin medida si no las podía cumplir a causa de la debilidad de su cuerpo y sobre todo porque el santo no obedecía las órdenes que eran ajenas a nuestra recta fe: el prodigioso Ignacio se hizo mártir. ${ }^{89}$

6. Después, cuando el tirano León hubo consumido su vida, aprovechó la oportunidad y pasó no mucho tiempo tratando con el clarividente Joanicio y con el taumaturgo Teófanes, confesor del Monasterio del Gran Campo, quienes le profetizaron que llegaría a ser arzobispo, lo que precisamente sucedió. ${ }^{90}$

\footnotetext{
${ }^{85}$ Tras una serie de derrotas y de malas decisiones políticas, Miguel I fue obligado a abdicar el 11 de julio del 813, pasando el poder a León V el Armenio, que lo mantuvo hasta su muerte en el 820: ODB 12091210, PmbZ \# 4244, PBE I Leo 15.

${ }^{86}$ Tonsura y castración a la fuerza fueron dos de las formas más habituales de convertirse en monje: Oltean (2020). El autor del encomio insiste en las virtudes que se atribuyen a los eunucos para hacerlos casi santos en vida por su castidad, cf. Ringrose (2003: 111-127), Tougher (2008: 69-79).

${ }^{87}$ Se omite el fin de Procopia: recluida en un monasterio fundado por ella, allí aguardó hasta ser condenada a muerte por sus conspiraciones: Janin (1969: 442-443).

${ }^{88}$ Como señalábamos en la introducción, este párrafo está fuera de lugar, dado que interrumpe la narración biográfica de los hechos. Con este palio de Santiago aparece representado Ignacio en el Menologio de Basilio II (Vat. gr. 1613, fol. 134r).

${ }^{89}$ Esta información sobre los años de juventud del futuro patriarca no figura en la Vita Ignatii y el autor del encomio no precisa el nombre el heresiarca ni el lugar donde se desarrollaron los hechos. No es frecuente en la hagiografía de patriarcas encontrar datos sobre la niñez o adolescencia de los protagonistas: Angelov (2009).

${ }^{90}$ En la Vit. Ign. 14 solo se nombra a Teófanes (PmbZ \#8197, PBE I Theophanes 18), mientras que Joanicio aparece en la Vit. Mich. Sync. 26 (BHG 1296), vaticinando lo mismo a su precedesor Metodio; sea como sea, además de un tópico (Pratsch, 2005: 290-297), es un anacronismo: Dvornik (1948: 18), Da Costa-Louillet (1954: 463), Mormino (2017/2018: 172-173). Joanicio es el principal monje-profeta de la primera mitad del s. IX: Timotin (2010: 182-194).
} 
7. En efecto, cuando a su muerte el tres veces dichoso Metodio dejó vacante la sede patriarcal, ${ }^{91}$ Teodora, la inspirada por Cristo, convocó el sínodo de los padres y con el beneplácito de senado y de todo el clero nombró patriarca a Ignacio. ${ }^{92}$

8. Durante muchos años el santo pastoreó la grey correctamente y al amparo de Dios. ¿Es por esto, entonces, por lo que el Diablo sintió envidia? ${ }^{93} \mathrm{Y}$ contra el buen pastor incitó al más poderoso de los gobernadores-me refiero al césar Bardas-, a quien apartó de la mística y veneranda comunión por haberse unido ilícitamente con cierta mujer. ${ }^{94}$ Por este motivo fue expulsado del trono y enviado al exilio, y después en la cárcel, además, encadenado y sometido al hambre. ${ }^{95}$

9. Por aquel entonces la tierra tembló por inspiración de Dios, ${ }^{96}$ soberano y creador de todo, para que reaccionaran los insensatos que votaron

\footnotetext{
${ }^{91}$ Metodio falleció el 14 de junio del 847 tras cuatro años en la sede patriarcal (ODB 1355; PmbZ \#4977, $P B E$ I Methodius 1), sucesor de Teófilo y, por tanto, iconodulo como él, aunque algo más beligerante; véanse, entre otros, Grumel (1935), Darrouzès (1987), Zielke (1999), Karlin-Hayter (2006), Bithos (2009), Prieto Domínguez (2020: 99-167).

${ }^{92} \mathrm{La}$ elección de Ignacio es muy controvertida ya que las fuentes pro-ignacianas, como el encomio, la Vit.

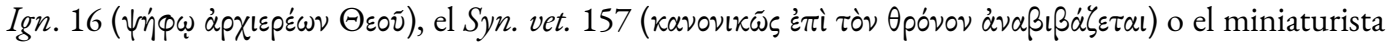
del "Escilitzes de Madrid" (fol. 76r: cf. Tsamakda, 2002: 118, fig. 185), insisten en una elección regular y canónica, mientras que los anti-ignacianos defendieron que no había sido elegido según los preceptos de la Iglesia de Constantinopla, siendo este uno de los motivos aducidos para su destitución: cf. Grumel (1939), Dvornik (1948: 18); el propio Dvornik (1973: 36) insiste en que, además, Roma no había tampoco confirmado la elección.

${ }^{93}$ El tópico antiguo de la "envidia de los dioses" ante las proezas de los hombres (cf. Dodds, 2001: 39-70) es modificado aquí con la "envidia del Diablo", siendo significativo el hecho de que precisamente se asocie a Focio y a sus secuaces con el Diablo en la Vit. Ign. 36, 57, algo frecuente en las fuentes anti-focianas, cf. Mango (1992: 220).

${ }^{94}$ Bardas (ODB 255-256, PmbZ \#791, PBE I Bardas 5) obtuvo la regencia, ante la incapacidad de gobernar de su sobrino Miguel III (ODB 1364, PmbZ \#4991, $P B E$ I Michael 11), cuando la emperatriz Teodora (ODB 2037-2038, PmbZ \#7286, PBE I Theodora 2), que hacía las veces de regente, fue destituida y expulsada del palacio en el 858, cf. Herrin (2001: 226-229), Varona Codeso (2009: 123-128), recluida en

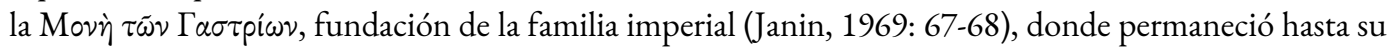
muerte: Karlin-Hayter (1990). El hecho aquí referido lo precisan otras fuentes: Bardas mantuvo relaciones ilícitas con su nuera y por ello Ignacio se negó públicamente a darle la comunión en la Epifanía (6 de enero) del año 858, cf. Dvornik (1966), Varona Codeso (2009: 152-155).

${ }^{95}$ La compilación más detallada de los suplicios sufridos por Ignacio está en la Vit. Ign. 17-37, aunque los refieren de forma puntual otras fuentes. La mención explícita de la cárcel puede aludir a la estancia de Ignacio en la prisión $\tau \grave{\alpha}$ Noúuspa de la capital, ubicada en las antiguas termas de Zeuxipo: Janin (1964: 222-224), Guilland (1969: 41-55). No obstante, el suplicio más degradante y humillante fue el encierro en el sarcófago de Constantino V Coprónimo, el emperador iconoclasta, según refiere la Vit. Ign. 35, cf. Grierson (1962: 53-54), Rochow (1994: 138-139), Varona Codeso (2009: 156-157), Prieto Domínguez (2014: 583-584).

${ }^{96}$ El séísmo se produjo en el 862, cuando ya había sido destituido oficialmente en el sínodo del 861.
} 
semejantes cosas contra el arzobispo y contra los sacerdotes que habían sido ajusticiados con él, pero no hubo quien lo interpretara, por más que la falacia de los gobernantes y la injusticia contra el santo fuesen evidentes gracias al abominable adulterio y el delito quedó oculto diciendo que él no había querido tonsurar a la madre y a las hermanas del soberano. ${ }^{97}$ No obstante, estos ya han recibido una amarga muerte por el justísimo juicio de Dios. $^{98}$

10. El que había sido injustamente condenado fue de nuevo sentado en la sacra sede con aclamación: cuando Basilio el Macedonio se hubo hecho con el trono imperial, enseguida llamó del duradero exilio al grande y magnífico Ignacio, el enviado de Dios, y, convencido por la petición del pueblo entero, lo elevó al trono patriarcal con una pompa y con una honra que no es posible describir. ${ }^{99} \mathrm{Al}$ enterarse de ello los jefes de las otras sedes patriarcales, se alegraron enormemente. ${ }^{100}$

11. Cuando así la brillante luminaria de la tierra hubo recibido de nuevo la sede patriarcal y pastoreado durante años la gran grey de Cristo, tras sobrevenirle una pequeña enfermedad, ya agotado por tantas cosas, descansa el sueño de Dios y se reúne con sus padres a una edad avanzada en

\footnotetext{
${ }^{97}$ En el encomio se alude a este hecho como si fuera una acusación infundada, cuando en realidad sí que Miguel III, aconsejado por Bardas, pretendió tonsurar a la fuerza a su madre y hermanas, si bien las fuentes varían en algunos detalles, cf. Garland (1999: 104-105), Herrin (2001: 227), Varona Codeso (2009: 124125).

${ }^{98}$ Como es sabido, Bardas murió durante una campaña y Miguel III fue asesinado por Basilio I el Macedonio (ODB 260, PmbZ \#832, PBE I Basilios 7) el 24 de septiembre del 867, cf. Vogt (1908: 40-46), Varona Codeso (2009: 171-181). Para la ambigua relación entre Miguel III y Basilio I véase Tougher (2016).

${ }_{99}$ Pura retórica, en realidad, dado que, al parecer, la restitución de Ignacio por parte de Basilio I encubría intereses diplomáticos, sobre todo congraciarse con la Sede Apostólica Romana, con quien las relaciones habían sido muy tensas durante el patriarcado de Focio: Vogt (1908: 211), Bury (1912: 203-204), Simeonova (1998: 260-261).

${ }^{100}$ Ciertamente, los patriarcados orientales firmaron la destitución de Focio en las actas del VIII Concilio Ecuménico y confirmaron la reinstauración de Ignacio, cf. Mormino (2017). En cuanto a la Iglesia autocefálica de Chipre, que no estuvo representada en el concilio, envió a Ignacio una carta firmada por el arzobispo Epifanio, texto que también se conserva en la "colección anti-fociana”. No obstante, los conflictos con la Sede Apostólica Romana por la evangelización de los búlgaros no cesaron con Ignacio e, incluso, fue amenazado con la excomulgación por Adriano II y Juan VIII: Vogt (1908: 228-232), Dvornik (1956: 119-120), Simeonova (1998: 266-271, 307-308). Sea como sea, los patriarcados orientales también mostraron su beneplácito a la restauración de Focio en el “Concilio de la Unión” del 879-880, cf. Meijer (1975: 60-61).
} 
el día de la conmemoración de Santiago, el hermano de Dios, y es enterrado en el Monasterio del Sátiro, que él mismo había fundado. ${ }^{101}$

12. Fue entonces cuando se produjo este milagro: aunque el mar estaba embravecido - pues era necesario trasladar por él sus sacrosantos restos-, sobrevino de repente la calma y así pudo cruzar con júbilo toda la gente que lo seguía hasta el Monasterio del Sátiro. ${ }^{102}$

13. Cuando todavía estaba vivo también llevó a cabo otro gloriosísimo milagro, pues, mientras se consumía en el exilio y era llevado de un sitio para otro, ${ }^{103}$ estando en Mitilene, en donde hay un río llamado Lico que por entonces fluía desbordado y era imposible de cruzar, alzando los brazos al cielo, hizo con una oración que al instante se calmara la corriente de agua. ${ }^{104}$ 14. Si pretendiera relatar algunos de cuantos prodigios realizó en vida y después de morir el imitador de Dios, no podría, como no se puede contar la arena de la playa, ${ }^{105}$ pero tú, verdadero hombre de Dios, pues a ti dirijo mi discurso, ojalá nos observes desde las alturas, tú que no eres inferior a un ángel, pues ya te has librado del cuerpo y te has despojado de los grilletes del barro $^{106}$. Y si incluso oculta bajo la carne como una capa tenías la valiosa providencia de comprender con autoridad gracias a tu mente, ¿cómo no podrás ahora velar por nosotros como Atanasio, ${ }^{107}$ la gran antorcha del orbe, y los maestros que están con él? Y aunque el antiguo sínodo confirmado por el voto de Dios decretó y así dejó por escrito que "si alguien dice que no se

\footnotetext{
${ }^{101}$ Ignacio murió el 23 de octubre del 877, justo la celebración de Santiago. Según la Vit. Ign. 76 su cuerpo fue expuesto a la veneración pública primero en Santa Sofía y después en la Iglesia de San Menas, situada en la acrópolis, cf. Janin (1969: 345-347). Sobre la localicación del Monasterio del Sátiro cf. supra introducción.

${ }^{102}$ Sobre este milagro cf. supra introducción.

${ }^{103}$ Según el registro de la Vit. Ign. 18-30, Ignacio pasó por Terebinto, Hierea, las prisiones $\tau \grave{\alpha}$ Прopótov y

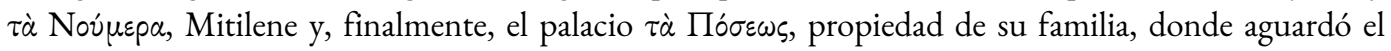
desarrollo del sínodo del 861, cf. Janin (1964: 415).

${ }^{104}$ Sobre este milagro, cf. supra introducción. Seis meses estuvo recluido Ignacio en Mitilene (Vit. Ign. 25), pero se desconoce el lugar exacto.

${ }^{105}$ A parte del tópico, sí es cierto que se le atribuyen numerosos milagros igualmente tópicos, cf. supra introducción.

${ }^{106}$ Sin olvidar la controversia angelológica que se daba en la época (cf. notas siguientes), cabría plantearse si la comparación con un ángel arrancaría aquí precisamente del hecho de que Ignacio fuera eunuco, dado que en Bizancio se asocia a los eunucos con otros seres especiales como los ángeles, cf. Ringrose (2003: 142-162), Tougher (2008: 106-107).

${ }^{107}$ Atanasio, patriarca de Alejandría (328-373), a quien se le atribuye un tratado Quaestiones ad Antiocbum ducem (CPG 2257) en el que trataría precisamente sobre la atribución a los ángeles de las apariciones de los santos.
} 
nos aparecen los santos, sino los ángeles, que sea anatematizado"108, tú, en cambio, vela por nosotros y protégenos.

Tabla 1: contenido del encomio

\begin{tabular}{|l|l|}
\hline Encomio (BHG 818) & Vita Ignatii (BHG 817) \\
\hline$\$ \$ 1-3$ familia & $\$ \$ 2-4$ \\
\hline$\$ 4$ anécdota 1 (Iacobi pallium) & $\$ 75$ \\
\hline$\$ 5$ formación & $\$ \$ 9-12$ \\
\hline$\$ 6$ profecías & $\$ 14$ \\
\hline$\$ \$ 7$ entronización & $\$ 16$ \\
\hline$\$ 8$ destitución & $\$ 17$ \\
\hline$\$ 9$ anécdota 2 (terrae motus) & $\$ 39$ \\
\hline$\$ 10$ reelección & $\$ \$ 53-59$ \\
\hline$\$ 11$ muerte y sepultura & $\$ 74-76$ \\
\hline$\$ 12$ miraculum 1 (post mortem) & $\$ 76$ \\
\hline$\$ 13$ miraculum 2 (ante mortem) & om. \\
\hline$\$ 14$ epílogo & om. \\
\hline
\end{tabular}

Tabla 2: miracula Ignatii

\begin{tabular}{|c|c|c|c|c|}
\hline mir. & $\begin{array}{l}\text { Vit. } \\
\text { Ign. }\end{array}$ & beneficiarios & tipo & medio \\
\hline 1 & $\$ 76$ & 2 mujeres & exorcismo & contacto con el féretro \\
\hline 2 & $\$ 76$ & los presentes & natural & llegada del féretro \\
\hline 3 & $\$ 80$ & muchacho poseído & exorcismo & visitación $(\dot{\varepsilon} \pi i \sigma \kappa \varepsilon \psi(\varsigma)$ \\
\hline 4 & $\$ 81$ & hombre epiléptico & curación & sueño (övap) \\
\hline 5 & $\$ 82$ & Hombre disentérico & curación & sueño (övap) \\
\hline
\end{tabular}

${ }^{108}$ Antes del pseudo-Atanasio, Eustracio de Constantinopla y Anastasio Sinaita habían planteado esa “usurpación de identidad” por parte de los ángeles, cf. Krausmüller (1998/1999), Dagron (2007: 211214), aunque la idea se fundamenta en la doctrina siria del "sueño de las almas", cf. Baranov (2016). El sínodo al que hace referencia el texto podría ser cualquier concilio local, dado que no se conservada nada semejante en los cánones conciliares. 
Álvaro Ibáñez Chacón

\begin{tabular}{|c|c|c|c|c|}
\hline 6 & $\$ 83$ & $\begin{array}{l}2 \text { mujeres con } \\
\text { agalaxia }\end{array}$ & curación & 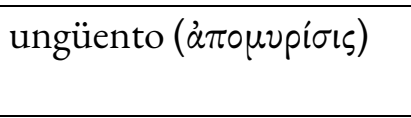 \\
\hline 7 & $\$ 84$ & mujer infértil & curación & 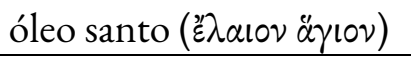 \\
\hline 8 & $\$ 85$ & estratego siciliano & auxilio & 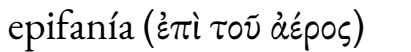 \\
\hline 9 & $\$ 86$ & mujer de parto & curación & $\begin{array}{l}\text { contacto con las reliquias } \\
\left(\pi \varepsilon^{\prime} \pi \lambda \circ \varsigma\right)\end{array}$ \\
\hline 10 & $\$ 87$ & enfermedades & curación & 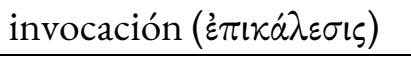 \\
\hline 11 & $\$ 87$ & posesiones & exorcismo & 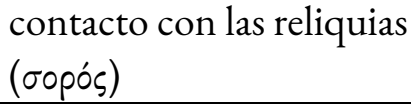 \\
\hline 12 & $\$ 87$ & impío fociano & punitivo & cólera divina \\
\hline
\end{tabular}

Álvaro Ibáñez Chacón

https://orcid.org/0000-0002-4126-5641

Universidad de Granada

alvaroic@ugr.es 


\section{Bibliografía}

AA.VV. (1612), Conciliorum Generalium Ecclesiae Catholicae tomus tertius, Romae.

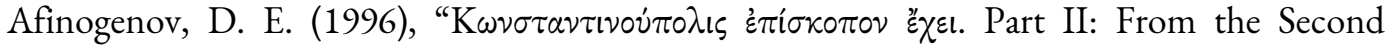
Outbreak of Iconoclasm to the Death of Methodios", Erytheia 17: 47-71.

Aigrain, R. (2000), L’hagiographie. Ses sources, ses méthodes, son histoire, 2a ed. Bruxelles: Société des Bollandistes.

Angelov, D. G. (2009), "Emperors and Patriarchs as Ideal Children and Adolescents. Literary Conventions and Cultural Expectations", en Becoming Byzantine. Children and Childhood in Byzantium (A. Papaconstantinou, A. M. Talbot, eds.), Washington: Dumbarton Oaks/Harvard University Press, pp. 85-126.

Assemanus, G. S. (1762), Bibliotheca iuris Orientalis canonici et civilis. Codex canonum ecclesiae Graecae, vol. I, Romae: Ex typographia Komarek.

Baranov, V. (2016), "Angels in the Guise of Saints: A Syrian Tradition in Constantinople”, Scrinium 12: 5-19.

Beck, H.-G. (1959), Kirche und theologische Literatur im byzantinischen Reich, München: Beck.

Binius, S. (1606), Concilia generalia et provincialia, vol. 3, Coloniae Agrippinae: Apud Ioannem Gymnicum.

Bithos, P. G. (2009), Saint Methodios of Constantinople. A Study of His Life and Works, Rollinsford: Orthodox Research Institute.

Brown, P. (1981), The Cult of the Saints, Chicago/London: University of Chicago Press.

Bury, J. B. (1912), A History of the Eastern Roman Empire: From the Fall of Irene to the Accession of Basil I, A.D. 802-867. London: Macmillan.

Canfora, L. (2001), Il Fozio ritrovato. Juan de Mariana e André Schott, Bari: Dedalo.

Canfora, L. (2004), Le vie del clasicismo III, Bari: Dedalo.

Casas Olea, M. (2020), Fuentes griegas sobre los eslavos II. Cristianización y formación de los primeros estados eslavos. 2. Fuentes epigráficas, epistolares, hagiográficas, Granada: Centro de Estudios Bizantinos, Neogriegos y Chipriotas.

Caseau, B. (2005), "Parfum et guérison dans le christianisme ancien: des huiles parfumées des médecins au myron des saints byzantins", en Les Pères de l'Église face à la science médicale de leur temps (V. Boudon-Millot y B. Pouderon eds.), Paris: Beauchesne, pp.141-192.

Cave, W. (1688), Scriptorum ecclesiasticorum historia literaria (sic), Londini: R. Criswell.

Chadwick, H. (2003), East and West. The Making of a Rift in the Church, Oxford: Oxford University Press.

Coleti, N. (1730), Sacrosancta Concilia, vol. X, Venetiis: apud Sebastianum Coleti et Jo. Baptistam Albrizzi Hieron. fil.

Cotsonis, J. A. (2011), “The Imagery of Patriarch Ignatios's Lead Seals and the rota Fortunae of Ninth-Century Byzantine Ecclesio-political Policies”, en Servant of the Gospel. Studies in Honor of His-All Holiness Ecumenical Patriarch Bartholomew, (T. Fitzgerald, ed.), Brookline: Holy Cross Orthodox Press, pp. 52-98.

Crimi, C. (2016), "Gregorio d'Agrigento e i suoi nemici. Il bios di Leonzio (BHG 707) e la riscrittura di Niceta David Paflagone (BHG 708)”, en Silenziose rivoluzioni. La Sicilia dalla Tarda Antichità al primo Medioevo (C. Giuffrida, M. Cassia eds.), Catania/Roma: Edizioni del Prisma, pp. 399-414. 
Crimi, C. (2018), "Emozioni e rappresentazione nei bioi dei patriarchi costantinopolitani Ignazio (BHG 817) ed Eutimio (BHG 651)", en Spazi e tempi delle emozioni. Dai primi secoli all'eta bizantina (P. B. Cipolla et al. eds.), Roma: Acireale, pp. 81-100.

Cunningham, M. (1991), The Life of Michael the Synkellos, Belfast: Belfast Byzantine Enterprises.

Da Costa-Louillet, G. (1954), "Saints de Constantinople aux VIII ${ }^{e}$ IX $^{e}$ et X $X^{e}$ siècles”, Byzantion 24: 453-511.

Dagron, G. (1981), “Quand la terre tremble...”, Travaux et Mémoires 8: 87-103.

Dagron, G. (2007), Décrire et peindre. Essai sur le portrait iconique, Paris: Gallimard.

Dagron, G. (2012), Idées byzantines, vol. I, Paris: Centre de recherche d'histoire et civilisation de Byzance.

Darrouzès, J. (1987), “Le patriarche Méthode contre les Iconoclastes et les Stoudites”, Revue des Études Byzantines 45: 15-57.

De Andrés, G. (1965), Catálogo de los códices griegos de la Real Biblioteca de El Escorial, vol. II, Madrid: Imprenta Helénica.

De Andrés, G. (1984), "Los copistas de los códices griegos del Cardenal de Burgos Francisco de Mendoza (†1564) en la Biblioteca Nacional”, Estudios Clásicos 88: 39-46.

De Andrés, G. (1986), Catálogo de los códices griegos de la Biblioteca Nacional. Madrid: Ministerio de Educación, Cultura y Deporte.

Delacroix-Besnier, C. (2003), "Philipe de Péra OP et Demetrios Kydonès", Nicolaus 30: 339345.

Delehaye, H. (1906), Les légendes hagiographiques, 2a ed. Bruxelles: Société des Bollandistes.

Delehaye, H. (1909), "Catalogus codicum hagiographicorum Graecorum Regii Monasterii S. Laurentii Scorialensis”, Analecta Bollandiana 28: 353-399.

Delehaye, H. (1912), "Saints de Thrace et de Mésie”, Analecta Bollandiana 31: 161-300.

Delehaye, H. (1933), Les origines du culte des martyrs, 2a ed. Bruxelles, Société des Bollandistes.

Delehaye, H. (1966), Les passions des martyrs et les genres littéraires, 2a ed. Bruxelles: Société des Bollandistes.

Delehaye, H. (1975), Les légendes grecques des saints militaires, 2a ed. New York: Arno Press.

Dodds, E. R. (2001), Los griegos y lo irracional, trad. esp. Madrid: Alianza.

Downey, G. (1955), "Earthquakes at Constantinople and Vicinity, A.D. 342-1454”, Speculum 30: 596-600.

Dumézil, G. (1996), Mito y epopeya III. Historias romanas, trad. esp., México: Fondo de Cultura Económica.

Dvornik, F. (1948), The Photian Schism. History and Legend, Cambridge: University Press.

Dvornik, F. (1956), The Slavs. Their Early History and Civilization, Boston: American Academy of Arts and Sciences.

Dvornik, F. (1966), "Patriarch Ignatius and Caesar Bardas”, Byzantinoslavica 27: 7-22.

Dvornik, F. (1973), "Photius, Nicholas I and Hardian II”, Byzantinoslavica 34: 33-50.

Efthymiadis, S. (2011), "Hagiography from the 'Dark Age' to the Age of Symeon Metaphrastes (Eight-Tenth Century)", en The Ashgate Research Companion to Byzantine Hagiography, I (S. Efthymiadis ed.), Farnham/Burlington: Ashgate, pp. 95-142.

Efthymiadis, S. (2018): "The Sea as Topos and as Original Narrative in Middle and Late Byzantine Hagiography”, en Ein Meer und seine Heiligen. Hagiographie im mittelalterlichen Mediterraneum (N. Jaspert, Ch. A. Neumann, M. di Branco eds.), Leiden/Boston: Brill, pp. 109-121. 
Émereau, C. (1924), "Hymnographi byzantini”, Echos d'Orient 23: 195-200, 275-284, 407-414. Eyice, S. (1959), “Contributions à l'histoire de l'art byzantine: quatre édifices inédites ou mal connus", Cahiers d'Archéologie 10: 245-250.

Featherstone, M., Signes Codoñer, J. (2015), Chronographiae quae Theophanis Continuati nomine fertur libri I-IV, Boston/Berlin: De Gruyter.

Féron, E., Battaglini, F. (1893), Codices manuscripti Graeci Ottoboniani, Romae: Ex Typographeo Vaticano.

Flusin, B. (1993), "L'hagiographie monastique à Byzance aux $\mathrm{IX}^{\mathrm{e}}$ et au $\mathrm{X}^{\mathrm{e}}$ siècles”, Revue Bénédictine 103: 31-50.

Franchi de'Cavalieri, P. et alii (1899), Catalogus codicum hagiographicorum Graecorum Bibliothecae Vaticanae, Bruxellis: Société des Bollandistes.

Garland, L. (1999), Byzantine Empresses. Women and Power in Byzantium, AD 527-1204, London/New York: Routledge.

Grierson, Ph. (1962), "The Tombs and Obits of the Byzantine Emperors (337-1042), with an Additional Note by C. Mango and I. Ševčenko”, Dumbarton Oaks Papers 16: 1-63.

Grotowski, P. Ł. (2010), Arms and Armour of the Warrior Saints. Tradition and Innovation in Byzantine Iconography (843-1261), Leiden y Boston: Brill.

Grumel, V. (1935), "La politique religieuse du patriarche saint Méthode”, Echos d’Orient 34: 385-401.

Grumel, V. (1939), “La genèse du schisme photien. La succession d'Ignace”, Rivista di Studi Bizantini e Neollenici 5: 179-184.

Grumel, V. (1958), La chronologie, Paris: Presses Universitaires de France.

Guilland, R. (1969), Études de topographie de Constantinople byzantine, 2 vols., Berlin/Amsterdam: Akademie Verlag y A. M. Hakkert.

Guilland, R. (1971), “Les Logothètes: Études sur l'histoire administrative de l'Empire byzantin”, Revue des Études Byzantines 29: 5-115.

Hardouin, J. (1714), Acta Conciliorum et Epistolae Decretales, vol. V, Parisiis: ex typographia Regia.

Hardt, I. (1810), Catalogus codicum manuscriptorum Graecorum Bibliothecae Regiae Bavaricae, Monachii: Seidel.

Hatlie, P. (2003), "The Encomium to Sts. Isaakios and Dalmatos by Michael the Monk (BHG 956d)", en EYKOГMIA. Studi miscellanei per il 75o di Vincenzio Poggi, S.J. (V. Ruggieri, L. Pieralli eds.), Soveria Manelli: Rubbettino Editore, pp. 275-312.

Herrin, J. (2001), Women in Purple. Rulers of Medieval Byzantium, Princeton y Oxford: Princeton University Press.

Hinterberger, M. (2014), "Byzantine Hagiography and Its Literary Genres. Some Critical Observations", en The Ashgate Research Companion to Byzantine Hagiography, vol. II (S. Efthymiadis ed.), Farnham y Burlington: Ashgate, pp. 25-60.

Hörandner, W. (1981), Der Prosarbythmus in der rhetorischen Literatur der Byzantiner, Wien: Österreichische Akademie der Wissenschaften.

Janin, R. (1923), “La banlieue asiatique de Constantinople”, Echos d'Orient 22: 182-198, 281 298.

Janin, R. (1964), Constantinople byzantine, 2a ed., Paris: Institut français d'études byzantines.

Janin, R. (1969), La géographie ecclésiastique de l'Empire byzantine. Les églises et les monastères, 2a ed. Paris: Institut français d'études byzantines. 
Kaeppeli, T. (1953), "Deux nouveaux ouvrages de Fr. Philippe Incontri de Péra O. P.," Archivum Fratrum Praedicatorum 23: 163-183.

Kaplan, M. (2000), “Le miracle est-il nécessaire au saint byzantin?”, en Miracle et Karāma. Hagiographies médiévales comparées (D. Aigle ed.), Turnhout: Brepols, pp. 167-196.

Karlin-Hayter, P. (1970), Vita Euthymii patriarchae CP, Bruxelles: Société des Bollandistes.

Karlin-Hayter, P. (1990), "La mort de Théodora”, Jabrbuch der Österreichischen Byzantinistik 40: 205-208.

Karlin-Hayter, P. (2006), "Methodios and his Synod", en Byzantine Orthodoxies. Papers from the Thirty-sixth Spring Symposium of Byzantine Studies (University of Durbam, 23-25 March 2002) (A. Louth, A. Casiday, eds.), Aldershot: Routledge, pp. 55-74.

Kazhdan, A. (1984), "Hagiographical notes", Byzantion 54: 176-182.

Kazhdan, A. (1999), A History of Byzantine Literature (650-850), Athens: National Hellenic Research Foundation.

Kazhdan, A. (2006), A History of Byzantine Literature (850-1000), Athens: National Hellenic Research Foundation.

Kolia-Dermitzaki, A. (2009), "Michael the Synkellos", en Christian-Muslim Relations. A Bibliographical History, I (D. Thomas et alii eds.), Leiden: Brill, pp. 627-630.

Krausmüller, D. (1998/1999), "God or angels as impersonators of saints: A belief and its contexts in the Refutation of Eustratius of Constantinople and in the writings of Anastasius of Sinai", Gouden Hoorn 6: 5-16.

Krausmüller, D. (2001/2002), "Fainting fits and their causes: a topos in two Middle Byzantine metaphraseis by Nicetas the Paphlagonian and Nicephorus Ouranos", Gouden Hoorn 9: 4-12.

Krausmüller, D. (2013), “The Vitae B, C and A of Theodore the Stoudite: Ther Interrelation, Dates, Authors and Significance for the History of the Stoudios Monastery in the Tenth Century", Analecta Bollandiana 131: 280-298.

Krötzl, C. (2000), "Miracles au tombeau - miracles à distance. Approches typologiques", en Miracle et Karāma. Hagiographies médiévales comparées (D. Aigle ed.), Turnhout: Brepols, pp. 557-576.

Krötzl, C. (2018), "Miracula post mortem: On Function, Contens, ad Typological Changes", en Miracles in Medieval Canonization Processes: Structures, Functions, and Methodologies (C. Krötzl, S. Katajala-Peltomaa eds.), Turnhout: Brepols, pp. 157-175.

Krumbacher, K. (1897), Geschichte der byzantinischen Litteratur, München: Beck.

Labbé, Ph., Cossart, G. (1671), Sacrosancta Concilia, vol. VIII, Lutetiae Parisiorum: Impensis Societatis Typographicae.

Labowsky, L. (1979), Bessarion's Library and the Biblioteca Marciana, Roma: Storia e Letteratura.

Lambros, S. P. (1895), Catalogue of the Greek manuscripts on Mount Athos, vol. I, Cambridge: University Press.

Lauxtermann, M. (1999), The Spring of Rhythm: An Essay on the Political Verse and Other Byzantine Metres, Wien: Österreichische Akademie der Wissenschaften.

Leemans, J. (2003), "Introduction”, en Let us die that we may live. Greek homilies on Christian martyrs from Asia Minor, Palestine and Syria (c. AD 350-AD 450) (J. Leemans et al. eds.), London y New York: Routledge, pp. 5-22.

Lehmann-Hartleben, K. (1922), "Archaeologisch-Epigraphisches aus Konstantinopel und Umgebung”, Byzantinisch-nengriechische Jabrbücher 3: 103-119. 
Leonardi, C., Placanica, A. (2012), Gesta Sanctae ac Universalis Octavae Synodi quae Constantinopoli congregata est, Firenze: Edizioni del Galluzzo.

Loenertz, R. J. (1948), “Fr. Philippe de Bindo Incontri O. P. du convent de Péra, inquisiteur en Orient”, Archivum Fratrum Praedicatorum 18: 265-280.

Loenertz, R. J. (1950), “Le panégyrique de S. Denys l'Aréopagite par S. Michel le Syncelle”, Analecta Bollandiana 65: 94-107.

Loukaki, M. (2005), "Le samedi de Lazare et les éloges annuels du patriarche de

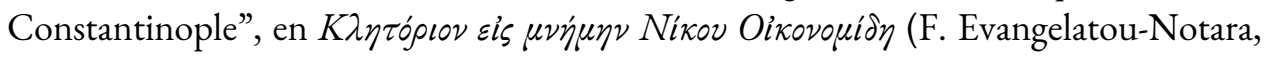
T. Maniati-Kokkini eds.), Athina/Thesssaloniki, pp. 327-345.

Loukaki, M. (2011), "L'image littéraire du patriarche de Constantinople chez les rhéteurs byzantins", en Zwei Sonnen am Goldenen Horn? Kaiserliche und patriarchale Macht im byzantinischen Mittelalter (M. Grünbart, L. Rickelt, M. M. Vučetič eds.), Münster: LIT-Verlag, pp. 65-78.

Lucà, S. (2012), "La silloge manoscritta greca di Guglielmo Sirleto. Un primo saggio di ricostruzione", Miscellanea Bibliothecae Apostolicae Vaticanae 19: 317-355.

Luzzi, A. (2019), "Osservazioni su una recente edizione della Vita Ignatii attribuita a Niceta David Paflagone", Travaux et Mémoires 23: 465-480.

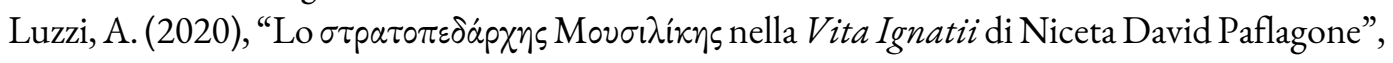
Rivista di studi bizantini e neoellenici 57: 133-145.

Maass, E. (1925), “Eunuchos und Verwandtes”, Rheinisches Museum für Philologie 74: 432476.

Mamboury, E. (1920), "Ruines byzantines de Mara, entre Maltépé et Bostandjik”, Echos d'Orient 19: 322-330.

Mango, C. - Hawkins, E. J. (1985), “The Mosaics of St. Sophia at Istanbul. The Church Fathers in the North Tympanum", Dumbarton Oaks Papers 26: 1-41.

Mango, C. (1992), "Diabolus Byzantinus", Dumbarton Oaks Papers 46: 215-223.

Mango, C. (1994), "Notes d'épigraphie et d'archéologie. Constantinople, Nicée”, Travaux et Mémoires 12: 347-350.

Mango, C. (2005), "Il santo”, en L'uomo bizantino (G. Cavallo ed.), 2a ed. Roma/Bari: Eunaidi, pp. 381-422.

Mansi, J. D. (1767), Sacrorum conciliorum nova et amplissima collectio, vol. XVII, Venetiis: A. Zatta.

Mansi, J. D. (1771), Sacrorum conciliorum noua et amplissima collectio, vol. XVI, Venetiis: apud A. Zatta.

Martínez Manzano, T. (2018), “La biblioteca manuscrita de Diego Hurtado de Mendoza: problemas y prospectivas”, Segno E̊ Testo 16: 315-433.

Martini, E. (1911), Textgeschichte der Bibliotheke des Patriarchen Photios von Konstantinopel, I. Die Handschriften, Ausgaben und Übertragungen, Leipzig: Teubner.

Matantseva, T. (1996), "Eloge des Archanges Michel et Gabriel per Michel le Moine (BHG 1294a)", Jabrbuch der Österreichischen Byzantinistik 46: 97-155.

Meijer, J. (1975), A Successful Council of Union. A Theological Analysis of the Photian Synod of 879-880. Thessaloniki: Patriarchal Institute of Patristic Studies.

Meinardus, O. F. A. (1970), "A Study of the Relics of Saints of the Greek Orthodox Church”, Oriens Christianus 54: 130-278.

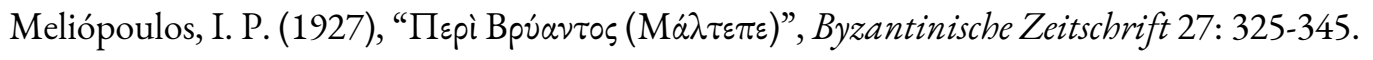


Mendes da Costa, M. B. (1902), Bibliotheek der Universiteit van Amsterdam. Catalogus der Handschriften, Amsterdam: Bibliotheek.

Mioni, E. (1981), Bibliothecae Divi Marci Venetiarum codices Graeci manuscripti. Thesaurus antiquus, vol. I, Roma: Istituto Poligrafico e Zecca dello Stato.

Mondrain, B. (1991/1992), "Copistes et collectionneurs de manuscrits grecs au milieu du XVI siècle: le cas de Johann Jakob Fugger d'Augsbourg”, Byzantinische Zeitschrift 84/85: 354-390.

Mormino, M. (2017), "La convocazione delle sedi patriarcali d'Oriente all'VIII Concilio Ecumenico (869-70): Antiochia e Gerusalemme", Peloro 2: 77-101.

Mormino, M. (2017/2018), Modello di Santità e Modelli di Empietà. Il patriarca Ignazio di Costantinopoli prima di Fozio: dalla fine della dinastia isauriana allo 'scisma' di Gregori Absestas (790-858), Tesi di Dottorato, Messina: Univerità degli Studi di Messina.

Narro, Á. (2015/2016), "Los beneficiarios de las curaciones de los santos en las primeras colecciones de milagros bizantinas (siglos iv-vii)", Revue des Études Tardo-antiques 5: 89-109.

Narro, Á. (2017), “Tópicos retóricos de las primeras colecciones bizantinas de milagros

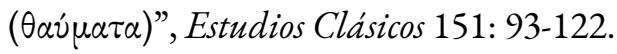

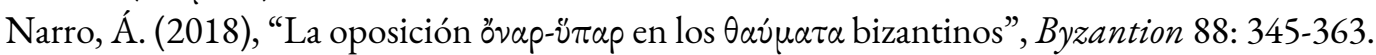

Narro, Á. (2019), El culto a las santas y los santos en la Antigüedad Tardia y la época bizantina, Madrid: Síntesis.

Narro, Á. (2019b), "Holy Water and Other Healing Liquids in the Byzantine Collections of Miracles", en Aigua $i$ vi a les literatures clàssiques i la seua tradició (J. J. Pomer Monferrer, H. Rovira eds.), Reus: Rhemata, pp. 121-143.

Oltean, D. (2020), Devenir moine à Byzance. Coutumes sociales, règles monastiques et rituels liturgiques, Leuven/Paris/Bristol: Peeters.

Omont, H. (1886), Catalogue des manuscrits grecs des bibliothèques de Suisse, Leipzig: Harrassowitz.

Omont, H. (1887), Catalogue des manuscrits grecs des bibliothèques des Pays-Bas. Leipzig: Harrassowitz.

Pargoire, J. (1901), "Les Monastères de S. Ignace et les cinq plus petits îlots de l'Archipel des Princes”, Izvestija Russkogo arheologičeskogo institute v Konstantinopole 7: 56-91.

Pernot, L. (1993), La rhétorique de l'éloge dans le monde gréco-romain, Paris: Institut d'études augustiniennes.

Pomaro, G. (1982), "Censimento dei manoscritti della Biblioteca di S. Maria Novella, II", Memorie Domenicane 13: 203-253.

Pratsch, T. (2005), Der hagiographische Topos, Berlin/New York: De Gruyter.

Prieto Domínguez, Ó. (2014), "Recounting Suffering: Patriarchal Tortures in Greek Medieval Literature”, en Ágalma. Homenaje a Manuel Garcia Teijeiro (Á. Martínez Fernández et al. eds.), Valladolid, Ediciones Universidad de Valladolid, pp. 581-586.

Prieto Domínguez, Ó. (2020), Literary Circles in Byzantine Iconoclasm, Cambridge: University Press.

Rader, M. (1604), Acta Sacrosancti et Oecumenici concilii octavi, Constantinopolitani quarti, Ingolstadii: Ex typographia Adami Sartorii. 
Ricci, A. (1998), "The Road from Bahdad to Byzantium and the case of the Bryas Palace in Istambul”, en Byzantium in the Ninth Century. Dead o Alive? (L. Brubaker ed.), Birmingham: Routledge, pp. 131-149.

Ringrose, K. M. (2003), The Perfect Servant. Eunuchs and the Social Construction of Gender in Byzantium, Chicago/London: University of Chicago Press.

Rochow, Ilse (1994), Kaiser Konstantin V. (741-775). Materialen zu seinem Leben und Nacbleben, Frankfurt am Main: Peter Lang.

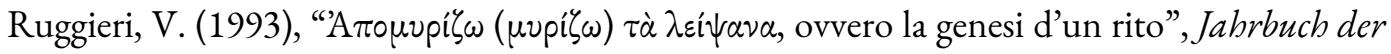
Österreichischen Byzantinistik 43: 21-35.

Russell, D. A., Wilson, N. G. (1981), Menader Rhetor, Oxford: Clarendon Press.

Rydén, L. (1986), "Byzantine Hagiography in the Ninth and Tenth Centuries. Literary aspects", Annales Societatis Litterarum Humaniorum. Regiae Upsaliensis: 69-79.

Ševčenko, I. (1962), “The Illuminators of the Menologium of Basil II”, Dumbarton Oaks Papers 16: 243-276.

Simeonova, L. (1998), Diplomacy of the Letter and the Cross. Photios, Bulgaria and the Papacy, 860s-880s, Amsterdam: A. M. Hakkert.

Smithies, A., Duffy, J. M. (2013), Nicetas David. The Life of Patriarch Ignatius, Washington: Dumbarton Oaks.

Stathakopoulos, D. C. (2002), "Rain Miracles in Late Antiquity: An Essay in Typology", Jabrbuch der Österreichischen Byzantinistik 52: 73-87.

Talbot, A.-M. (2015), "The Relics of New Saints: Deposition, Translation, and Veneration in Middle and Late Byzantium", en Saints and Sacred Matter: The Cult of Relics in Byzantium and Beyond (C. Hahn, H. A. Klein eds.), Whasington Dumbarton Oaks, pp. 215-230.

Tamarkina, I. (2006), "The Date of the Life of Patriarch Ignatius Reconsidered", Byzantinische Zeitschrift 99: 615-630.

Tiftixoglu, V. (2004), Katalog der griechischen Handschriften der Bayerischen Staatsbibliothek München, vol. I, Wiesbaden: Harrassowitz.

Timotin, A. (2010), Visions, prophéties et pouvoir à Byzance, Paris: Centre d'études byzantines, néo-helleniques et sud-est européennes.

Tougher, S. (2004), "Holy Eunuchs! Masculinity and Eunuch Saints in Byzantium”, en Holiness and Masculinity in the Middle Ages (P. H. Cullum, K. J. Lewis eds.), Cardiff: University of Wales Press, pp. 93-108.

Tougher, S. (2008), The Eunuch in Byzantine History and Society, London/New York: Routledge.

Tougher, S. (2016), "Michael III and Basil the Macedonian: Just Good Friends?", en Desire and Denial in Byzantium. Papers from the Thirty-first Spring Symposium of Byzantine Studies, University of Sussex, Brighton, March 1997 (L. James, ed.), 2a ed., London/New York: Routledge, pp. 149-158.

Tsamakda, V. (2002), The Illustrated Chronicle of Iohannes Skylitzes, Leiden: Alexandros Press. Valiavitcharska, V. (2013), Rhetoric and Rhythm in Byzantium. The Sound of Persuasion, Cambridge: University Press.

Van de Vorst, C., Delehaye, H. (1913), Catalogus codicum hagiographicorum graecorum Germaniae Belgii Angliae, Bruxellis: Société des Bollandistes.

van Hoof, G. (1886), "Encomium in s. Agathonicum Nicomediensem martyrem", Analecta Bollandiana 5: 396-415. 


\section{Álvaro Ibáñez Chacón}

van Uytfanghe, M. (2005), "La biographie classique et l'hagiographie chretienne antique tardive”, Hagiographica 12: 223-248.

Varona Codeso, P. (2009), Miguel III (842-867). Construcción histórica y literaria de un reinado, Madrid: Centro Superior de Investigaciones Científicas.

Vinson, M. P. (1998), "Gender and Politics in the Post-Iconoclastic Period: The Lives of Antony the Younger, the Empress Theodora, and the Patriarch Ignatios", Byzantion 68: 469515.

Vogt, A. (1908), Basile I' empereur de Byzance (867-886) et la civilisation byzantine à la fin $d u$ $I X^{e}$ siècle, Paris: Picard.

Von Falkenhausen, V. (2018), "Il mare nell'agiografia italogreca", en Ein Meer und seine Heiligen. Hagiographie im mittelalterlichen Mediterraneum (N. Jaspert, Ch. A. Neumann, M. di Branco eds.), Leiden/Boston: Brill, pp. 137-157.

Vryonis Jr., S. (1981), "The Panegyris of the Byzantine Saints", en The Byzantine Saint (S. Hackel ed.), London: University of Birmingham, pp. 196-227.

Walter, C. (2003), The Warrior Saints in Byzantine Art and Tradition, Aldershot: Routledge.

White, M. (2013), Military saints in Byzantium and Rus, 900-1200, Cambridge: University Press.

Zacharova, A. (2009), "Los ocho artistas del Menologio de Basilio II", en El Menologio de Basilio II (Città del Vaticano, Biblioteca Apostolica Vaticana, Vat. gr. 1613). Libro de Estudios con ocasión de la edición del facsimil (F. D’Aiuto dir.), versión española a cargo de I. Pérez Martín, Madrid: Testimonio, pp. 131-195.

Zielke, B. (1999), “Methodios I.”, en Die Patriarken der ikonoklastischen Zeit: Germanos I. Methodios I. (715-847) (R.-J. Lilie, ed.), Frankfurt an Main: Peter Lang, pp. 216-230. 